University of San Diego

Digital USD

1997-08-01

\title{
Clashing Cultures or Collaborating Networks: A Study of Organization Culture in Breast Cancer Prevention
}

Joseph V. Raffa EdD

University of San Diego

Follow this and additional works at: https://digital.sandiego.edu/dissertations

Part of the Leadership Studies Commons

\section{Digital USD Citation}

Raffa, Joseph V. EdD, "Clashing Cultures or Collaborating Networks: A Study of Organization Culture in Breast Cancer Prevention" (1997). Dissertations. 630.

https://digital.sandiego.edu/dissertations/630

This Dissertation: Open Access is brought to you for free and open access by the Theses and Dissertations at Digital USD. It has been accepted for inclusion in Dissertations by an authorized administrator of Digital USD. For more information, please contact digital@sandiego.edu. 
CLASHING CULTURES OR COLLABORATING NETWORKS:

A STUDY OF ORGANIZATION CULTURE IN BREAST CANCER PREVENTION

\author{
by \\ Joseph V. Raffa \\ A dissertation submitted in partial fulfillment \\ of the requirements for the degree of \\ Doctor of Education
}

University of San Diego

August 1997

Dissertation Committee

Jerome J. Ammer. Ph.D., Director

Mary Abascal-Hildebrand, Ed.D.

Mary W. Scherr, Ph.D.

Diane Hatton. D.N.Sc. 


\section{ABSTRACT}

CLASHING CULTURES OR COLLABORATING NETWORKS: A STUDY OF ORGANIZATION CULTURE IN BREAST CANCER PREVENTION Joseph Raffa, Ed.D., University of San Diego, 1997. Director: Jerome Ammer, Ph.D.

This study explored organization culture and policy within the community/metaorganization formed by diverse arenas of breast cancer prevention. The subject area of breast cancer was chosen due to its social significance as a major health issue. The phenomenon of organization culture was chosen due to the interest of the researcher, and the implications for collaborative leadership within the cancer prevention community.

The community/metaorganization includes formal and informal relationships between organizations that have a role in the prevention of breast cancer. Included were individuals working/volunteering in different arenas across organizations with undefined lines of authority and communication. Four arenas of involvement were determined significant: (a) primary prevention, (b) secondary prevention, (c) tertiary prevention, and (d) advocacy. Qualitative methodology was applied to develop a grounded theory inductively, primarily from interviews and a focus group.

The findings of the study suggest nine distinct organization cultures exist within the breast cancer prevention community/metaorganization. The cultures observed related to each other based on their alignment to the three prevention policy arenas: primary, secondary, and tertiary. A dominant culture emerged referred to as conventional wisdom. Emergent was a significant complex interaction of conventional wisdom with the advocacy movement of the early 1990s. This interaction consisted of a clashing that resulted in differentiated culture outcomes for advocacy: radical activism, political activism, and outreacher.

The study presents examples of both clashing cultures and collaborating networks, grounded in the data collected from participants. Leadership emerged from the data as a major theme/category expressed in different ways by participants from different organization culture perspectives. 
Copyright 1997 Joseph V. Raffa 
This dissertation is dedicated to the memory of my mother and father Mary and Charles Raffa.

For Peppina, whose battle with cancer inspired the journey, and to Maria, Natalie, Ben, and Luke for giving me the reason I am here. 


\section{TABLE OF CONTENTS}

\section{CHAPTER I}

Statement of the Problem..................................................... 1

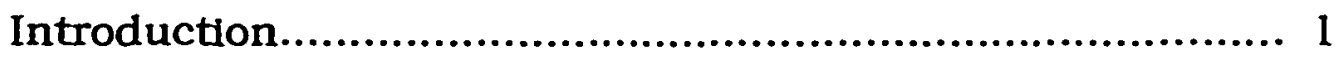

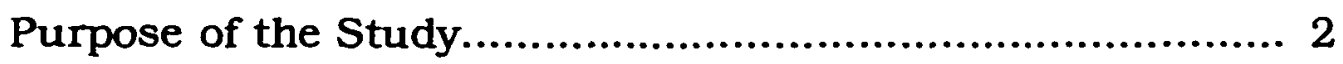

Research Questions...................................................... 3

Significance................................................................... 4

\section{CHAPTER II}

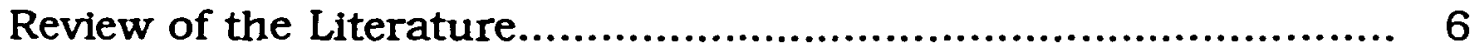

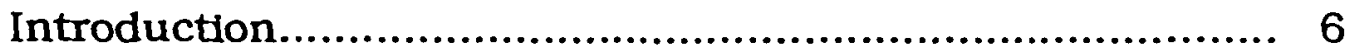

Organization Theory ...................................................... 7

Organizational Culture and Leadership Theory.................... 10

Organization Culture Defined................................. 10

The Relationship between Culture and Leadership....... 11

Leadership Defined.............................................. 11

Cancer Prevention Empirical Data and Current Views........... 14

Organizational Leadership in the Context of Cancer.............. 17

The Grand Scope: Larger Issues and Trends........................ 19

\section{CHAPTER III}

Research Design \& Methodology......................................... 23

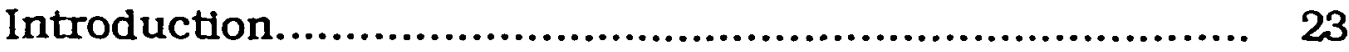

Methodology Overview................................................... 24

Study Activity Context.............................................. 25

Research Design........................................................ 26

Data Collection................................................ 26

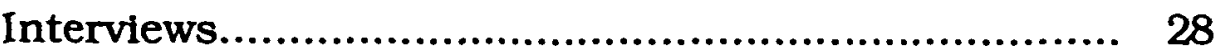

Protection of Human Subjects.............................. 29 
Data Analysis................................................ 29

Overview/Grounded Theory Defined................ 29

Applied Methodologies................................ $\quad 30$

Summary............................................................. 31

CHAPTER IV

Cultures: Descriptions and Connections................................ 32

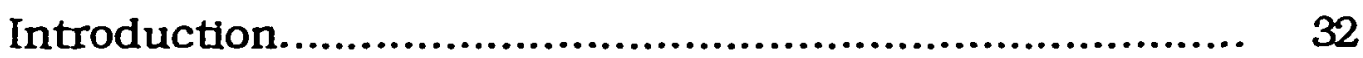

Summary of Findings.............................................. 32

Culture Descriptions.................................................... 34

Organizational Connections........................................ 41

Informal Support Connections....................................... 43

Cultural Actors and Crossovers.................................... 46

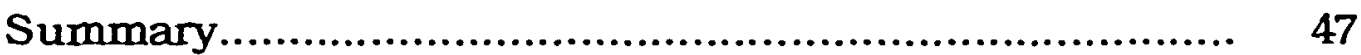

\section{CHAPTER V}

Clashing Cultures. Collaborations, and Leadership................... 48

Introduction......................................................... 48

Clashing Cultures................................................. 48

Research Idealism vs Conventional Wisdom............ 48

Radical Activism vs Conventional Wisdom.............. 51

Business vs Clinical Medicine............................. 52

Business vs Patient Care/Outreacher.................... 53

Collaborating Networks............................................. 55

A Collaborattve Initiative.................................. 55

Grassroots Advocacy......................................... 56

A Community Clinic.......................................... 58

"Getting Within" the Community......................... 58

Leadership Expression and Theory................................ 59

Leadership as "Tip of the arrow"........................... 59

Leadership as "Project Lead"................................ $\quad 60$

Leadership as "Common Sense"........................... 61

Leadership as "Getting the Product to Market"........ 62 
Organizational Culture and Survival............................. 66

Summary...................................................... 66

CHAPTER VI

Transformative Change Theory ............................................... 70

Introduction................................................. 70

The Advocacy Movement....................................... 71

Interaction and Outcomes from Clashing Cultures... 72

Summary of Theory Elements............................... 74

Summary .................................................... 74

\section{CHAPTER VII}

Researcher's Perspective................................................... 76

My Role as Cancer Registry Manager and Activist... $\quad 76$

Did We Take the Wrong Turn?........................... 79

Paradigms, Metaphors, and Meanings.................. $\quad 80$

Key Linkage: The Expanding Collage Metaphor....... 82

Leadership, Culture, and Change........................ 84

CHAPTER VIII

Summary, Conclusions, Implications, Recommendations.......... 86

Summary .................................................... 86

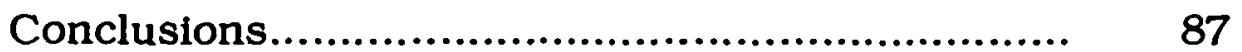

Implications................................................ 88

Recommendations........................................ 89 


\section{A LIST OF FIGURES}

FIGURE III-1: Research Process

FIGURE III-2: Study Activity Context

FIGURE IV-1: Formal Connections

FIGURE IV-2: Support Connections/Prevention Arenas

FIGURE IV-3: Support Connections/Breast Cancer Advocacy

FIGURE VI-1: Differentiated Outcomes from Advocacy

FIGURE VII-1: Collage of Participant Perspectives
B CONSENT FORM
C DEFINITION OF TERMS
D BACKGROUND OF THE RESEARCHER 


\section{Chapter I: Statement of the Problem}

\section{Introduction}

In 1971, the federal government launched a program to end cancer. After twenty-four years, and twenty billion dollars expended, more than a thousand people still die of cancer every day in the United States. While most other diseases are on the decline, cancer is on the rise: "If present trends continue. cancer will become the First World's leading cause of death sometime in the Twenty-first Century" (Proctor, 1995, p. 1).

Contributing to the high incidence is breast cancer. The Special Commission on Breast Cancer reported that during the 1970s and 1980s, breast cancer incidence rose by 21 percent among women of all ages in the United States (President's Cancer Panel. National Institutes of Health report. October 1993). These data have contributed to a sense of urgency to find answers. The urgency, combined with increasing frustration among breast cancer victims (patients and family) led to a breast cancer advocacy movement in the early 1990s. One major outcome of advocacy has been a renewed interest in cancer prevention.

Breast cancer advocacy has reshaped cancer prevention. Before the successful launching of advocacy, funding levels for cancer prevention were meager compared to basic research and treatment related funding. The focus change was based on the aggressive stance by activists on the eradication of the disease. As new players in the world of cancer prevention, they were not willing to accept the status quo. They viewed the problem as "life and death" in contrast to entrenched institutions that are more conservative.

The breast cancer prevention community (to be referred to in this study as the BCP community) consists of diverse organizations and disciplines. Examples are: (a) advocacy groups that promote awareness and funding, (b) cancer researchers, (c) cancer data collectors/reporters, (d) federal and state public health officials, (e) fund raising organizations, and (f) healthcare 
providers. The common mission of these organizations is to decrease the mortality and incidence (occurrence) of cancer.

Many theories have been advanced as to why these organizations have not been more effective in achleving their mission. One theory is the insufficiency of research funding. More funding would increase the number and depth of studies, increasing the likelihood of significant results. Another theory is that the organizations in the community have conflicting charters, resulting in inefficiency. Schopler (1988) notes from her research of cancer organizations that difficulties exist in coordinating organizational activities.

This study addresses the nature of organizational interaction and other related issues that emerged in the activity area defined as the BCP community. Various arenas of organizational involvement were tentatively defined at the initiation of the research, and validated/updated in the study. The study explores the interaction of individuals working and volunteering in these arenas creating an informal structure of relationships distinct from the formal organizations.

Within this study, six arenas of organizational involvement were tentatively defined to operate in the BCP community: (a) primary prevention. (b) secondary prevention. (c) tertlary prevention, (d) information support, (e) funding, and (f) advocacy. These arenas and each organizational entity within them exhibit characteristics related to culture, collaboration, and policy shaping. Development of an understanding of the interrelationships and dynamics within, between, and among the various arenas and organizations was the central aim of this study.

\section{Purpose of the Study}

The purpose of this study is to develop theory that may add new knowledge to the nature of interaction within, between, and among organizational arenas operating in the $\mathrm{BCP}$ community. The research seeks to explore the arenas and the nature of culture, collaboration, and policy shaping. 
The methodology is qualitative and naturalistic, employing grounded theory techniques. Data are collected primarily through interviews with participants representing different arenas in the BCP community. The approach is grounded because it seeks to develop theory "grounded" in the actual experience of the individuals working in the study activity environs. "A grounded theory is one that is inductively derived from the phenomenon it represents" (Strauss, Corbin, 1990, p. 23). The phenomenon explored in this study is the interaction of organizations within various functional arenas that share the common mission of preventing breast cancer. The nature of the interaction relates to culture, collaboration, and policy shaping in the context of a dynamic metaorganization consisting of diverse organizations and individuals at different points in time.

Metaorganization for this study was perceived as the formal and informal relationships formed by the interaction of individuals from different arenas and organizations. Organization culture was perceived in this study as socially constructed realities that influence (and are influenced by) the language. values, norms, folklore, and other social practices communicated within the organizational framework. Influence is considered dynamic in this definition based on the assertion by Bohannan (1995) that unless a culture is changing. open to new input and influence, it is a dead culture. Collaboration was perceived as unifying cooperation and communication that transforms conflict into consensus, and contributes to mission accomplishment.

\section{Research Questions}

Grounded theory qualitative research dictates a certain type of research question. Bowers (1988) suggests "general" research questions to avoid specificity that would assume the researcher already knows the nature of the object or phenomenon. The general research questions for this study were:

1. What are the culture relations within, among, and between the different arenas of the breast cancer prevention community? 
2. How is policy influenced by the culture relations?

3. What are the formal and informal organization structures that shape the relationships?

\section{Significance}

Breast cancer is a major health issue with significant social implications. The social implications stem from the unrelenting chronic nature of the disease. There is public concern and growing dissatisfaction with cancer organizations that are charged with prevention.

Breast cancer advocacy has had a transforming effect on the arenas of prevention due to the renewed attention by advocates. The advocacy movement has raised awareness of the increased need for research funding that is focused more on eradication of the disease.

Schopler (1988) informs us from her research in community clinical oncology programs that: "Cancer continues to pose a major health risk ... future goals will not be met without a better understanding of the social technology required to coordinate inter-organizational activities related to cancer research, treatment, and prevention" (p. 1). Myers (1989) concluded from his research on organizational collaboration that success in forming coalitions. with a diverse mix of entities (medical center, church group etc), is influenced by the social structural factors within the various groups involved.

Basic research and prevention research often represent competing entities for funding. In addressing this conflict of emphasis between basic research and prevention, Proctor (1995) states: "... the poverty of prevention ... stems partly from the fact that effective prevention requires changes not just in research priorities but also in deeply ingrained personal habits and the logic of business enterprise" (p. 266). He continues with: "knowledge about cancer is not in very short supply. What is needed are thoughtful and confident steps to reorient cancer policy" (p. 270). Proctor is adding to the growing body of concern that the nation's research funding may not be allocated, within 
BCP Culture/Leadership

current policy dictates, to provide the optimum return from the investment.

This study aims to develop theory about the nature of organizational interaction within the $\mathrm{BCP}$ community relating to culture, collaboration, and policy shaping. Furthermore, this study may add to the broader understanding of how organization cultures, and the nature of their collaboration, affect the operational effectiveness of diverse organizations sharing a common mission. 
BCP Culture/Leadership

\section{Chapter II: Review of the Literature}

\section{Introduction}

The literature review suggests five research contexts that are foundational to the research: (a) organization theory, (b) organizational culture and leadership, (c) organizational leadership in the context of cancer, (d) empirical research and current views in cancer prevention, and (e) trends and issues of a cultural and sociological nature relating to organization and society.

The review establishes foundational concepts with theories that provide insight into the nature of organization as a socially constructed means to achieving collective aims. Organization culture from various perspectives will be examined to develop a broad encompassing view that will provide foundation for the study.

The review includes organizational leadership and change from the context of cancer. The breast cancer advocacy movement introduced transforming change to cancer prevention as well as other areas of cancer. Therefore, it is appropriate to review concepts of organization change and the implications for leadership and culture.

The phenomenon being studied is organizations in activity arenas of cancer prevention, with attention to breast cancer advocacy. Therefore, the review includes both empirical research on the subject activity, and contemporary literature that provides current views from the perspective of political history, and breast cancer advocacy.

Lastly, the review includes a macro view of the subject from the perspective of futurists, sociologists, and anthropologists. These perspectives give insight into factors that affect the activity area being studied on a broader scale. 


\section{Organization Theory}

Organizational theorists offer many perspectives on the role of "organization" in creating and sustaining industrial society. Mumby (1988) provides the grand perspective for viewing the role of organization:

The main engine of western civilization ... is at once the most

indispensable and the least celebrated. It is not money, nor technology. nor even number. It is not science .... It is the concept of organization. (p. 1)

The pervasiveness and importance of organization as a means for collective achievement is developed in many ways. Organization has been defined in the following ways: a concept for mutual endeavor, a framework of functions, a social construct of individuals, a hierarchy of workers with defined spans of control, a military model for winning wars. Theorists have taken different approaches to understanding the nature of organization and organizations.

Morgan (1986) provides a comprehensive theoretical framework of organizations by creating different images or lenses. He theorized that six major images represent how organizations are perceived: as machines. organisms, brains, political systems, cultures, and psychic prisons. He explains that the models are not solitary actors; rather, all coexist in some manner in every organization.

The machine metaphor described by Morgan (1986) is the classic model that evolved out of the industrial era driven by scientific management. The fundamental theory is that organizational functions are analogous to the parts of a machine. Each has a specific role or task to perform to maintain overall operability. This is the basis of the bureaucratic policy and procedure model existing in the majority of organizations. The benefit is efficiency, the negative is the dehumanization of the individuals filling the roles or boxes. Morgan develops the organism model based on the theory that all elements of the universe can be reduced to a cybernetic (systems theory) unit. The unit consists of input, process, output, and feedback. An open system is one in 
which refreshed input revitalizes the organism and growth is possible. The benefits of this model are the insights derived from knowing how systems work and interact with key implications in adaptation to internal and external environments. The pitfalls involve the esoteric nature of the model and the difficulty of putting the theory into practice.

The brain model, according to Morgan (1986), views the organization as an information processing system with decision-making at the core of change and growth. A benefit is the emphasis on learning, and learning to learn with implications to self organization. Another benefit is that this model incorporates current computing and telecommunication technologies; i.e.. the technologies that presently "sit on our desks" make this model more feasible and identifiable in post-modern terms. The downside to this model is the oversimplification it represents and the exclusion of human factors. The organization as political system model, as described by Morgan, is grounded in the reality that individuals and groups internal and/or external to the entity will have interests, create conflict, and exert power. Politics is central to organizational interaction; it is not an "optional and dysfunctional extra." It is there to be reckoned with as long as humans occupy those chairs and boxes within organizations. The benefit is the recognition of human behavior as it plays out in organizational settings. and the simple fact that it often is the way things get done. Therefore, an awareness of the model allows us to work with it and not to deny it.

Morgan's (1986) image of the culture metaphor points toward another means of creating organized activity "by influencing the language, norms, folklore, ceremonies. and other social practices that communicate the key ideologies. values, and beliefs guiding action" (p. 130). He describes how cohesive groups are those that arise around shared understandings, while fragmented groups tend to be those characterized by multiple realities. Morgan does not view culture as static; it is an active. living phenomenon through which people create and recreate the worlds in which they live. He poses central 
questions to organizational analysis that are rooted in an understanding that culture creates systems of shared meaning: "What are the shared interpretive schemes that make organization possible? Where do they come from? How are they created, communicated, and sustained?" (Morgan, 1986, p. 131).

With one (Morgan's) theoretical framework of organization models developed, the concept of culture will now be expanded with other perspectives. This is followed by definitions of culture in the context of organization.

One of the first definitions of culture comes from early anthropologist. E. B. Tylor (1871): "Culture, or civilization, ... is that complex whole which includes knowledge, belief, art, law, morals, custom, and other capabilities and habits acquired by man as a member of society" (reprinted in Kroeber and Kluckhohn, 1952, p. 81).

The field of social science has given us another slant. The term "symbolic interaction" was coined by Blumer in 1937, and posits a notion that reality is socially constructed. Therefore, reality and meaning for an individual or a collective of individuals "is derived from, or arises out of, the social integration that one has with one's fellows" (Blumer, 1972, p. 67). Schein's (1985) definition reflects the existence of a pattern of basic assumptions that are created and developed by an organization/group.

Deal and Kennedy (1982) are known for popularizing the term "corporate culture." They include a number of elements that make up organization culture: values, business environment, heroes, rites and rituals, and cultural networks (for organizational communication) - with values as the core element. Tichy (1983) shared the view that values is the essence of culture. He defined the phenomenon as: "cultural systems of values with shared symbols and shared cognitive schemes which tie people together and form a common organization culture" (p. 7). 
BCP Culture/Leadership

\section{Organizational Culture and Leadership Theory}

As a bridge between the review of organization theory and leadership in the context of cancer, a review of the literature that informs us about culture and leadership in the context of organizational/group settings follows. The issue of culture emerged from the findings of this research. The issue of leadership emerged from this research based on follow-up interviewing, and the implications for leadership in the breast cancer advocacy movement.

Considered a social movement. breast cancer advocacy effected change in many facets of cancer work: research, prevention, therapy, and support. This research is focused on cancer prevention as one activity area affected by the movement.

\section{Organization Culture Defined}

What is organization culture and why is it important? Schein's (1985) definition includes two basic elements: the need of an organization to adapt to its external environment, and its need to have integration within the organization. He theorizes that an organization/group depends on basic assumptions at a deep level to define how it copes with these two elements. His definition is:

Culture is a pattern of basic assumptions - invented, discovered, or developed by a given group as it learns to cope with its problems of external adaptation and internal integration - that has worked well enough to be considered valid and, therefore, to be taught to new members as the correct way to perceive, think, and feel in relation to those problems (p. 9).

Schein (1995) explains behavior that is ineffective in organizations, often threatening to survival, with this discussion of culture:

If we understand the dynamics of culture, we will be less likely to be puzzled. ... when we encounter the unfamiliar and seemingly irrational behavior of people in organizations, and we will have a deeper 
understanding not only of why various groups of people or organizations can be so different but also why it is so hard to change them." (pp 272-273)

He describes the role of leadership in the context of organization culture and change as the key element that is responsible for "the creation, the management, and sometimes even the destruction of culture" (p. 273).

\section{The Relationship of Culture and Leadership}

The relationship between organization culture and leadership is next explored in more detail by Schein (1995). Schein defines the relationship between leadership and culture as follows:

Neither culture nor leadership. when one examines each closely, can really be understood by itself. In fact, one could argue that the only thing of real importance that leaders do is create and manage culture and that the unique talent of leaders is their ability to understand and work with culture. (p. 273)

He further develops this idea by stating that leaders are not the only creators of culture. Culture, he says: " is the result of a complex group learning process that is only partially influenced by leader behavior" (p. 273). But he places leadership in a responsible and powerful role with the statement:

... if the group's survival is threatened ... it is ultimately the function of leadership to recognize and do something about the situation. It is in this sense that leadership and culture are conceptually intertwined. (p. 273)

With the relationship between organization culture and leadership established. leadership as a process requires definition.

\section{Leadership Defined}

Leadership may be necessary to affect culture in organizations. But what specifically is leadership? Leadership has been researched from various 
theoretical frameworks. A review of the literature includes theories by Greenleaf (1977), Rost (1993), Watkins (1989), and Foster (1989).

Greenleaf (1977) characterized leadership as: "going out ahead to show the way" (p. 96). He viewed great leaders as servants first. His theory of leadership extended to everyone in the organization, from the chief executive to the least skilled individual. In contrast to management and authority. "leadership is available to everyone ... . who has the competence, values, and temperament for it" (p. 96).

Rost (1993) provided a definition of leadership, and a detailed architecture for understanding his conception of leadership. He theorized that leadership is an influence relationship, not attributable to characteristics or traits of individuals. His definition is:

Leadership is an influence relationship among leaders and followers who intend real changes that reflect their mutual purposes. (p. 102) He stated that four elements are required for leadership to exist. and defined sub-element descriptions.

1. The relationship is based on influence.

2. Leaders and followers are the people in the relationship.

3. Leaders and followers intend real changes.

4. Leaders and followers develop mutual purposes.

A third conception describes leadership as a "dialectic relationship in the social construction of reality" (Watkins, 1989, p. 27):

When seen as a dialectic, leadership implies the presence of considerable tensions and contradictions which, when resolved, lead to the continual transformation of the relationship. (p. 27)

Watkins' view of leadership is distinctively dynamic in nature, with leaders coming to the "forefront" to resolve tensions as they arise. It is dynamic in the sense of ongoing and transforming human interaction.

Watkins responded to the "traditional functionalist" view of leadership in his research as no longer appropriate to the current state of organizations. 
He suggested that the more static traditional model rooted in the industrial era be replaced with a transformative model to:

foster an organizational community in which all the members of the organization have the capacity and opportunity to be leaders and where there is a common concern for empowerment and the betterment of the human condition. (pp. 32-33)

Foster (1989) examined leadership in the context of community. He described the search for community as an "ongoing and creative enterprise in which ... agents continually re-create social structure" (p. 45). He related leadership to community:

The idea that leadership occurs within a community suggests that ultimately, leadership resides in the community itself" (p. 49). Foster suggested that:

It is an enduring feature of human life to search for community; to attempt to establish patterns of living based on mutual need and affection. development and protection.(p. 48)

He shared a belief similar to Watkins that the process is ongoing, interactive, dynamic, and constantly recreating itself forming new social structure. He defined the conceptual demands for leadership this way: "leadership must be critical, transformative, educative, and ethical" (p. 50). Foster summarized leadership in the context of community:

Leadership, in the final analysis, is the ability of humans to relate deeply to each other in the search for a more perfect union. Leadership is a consensual task, a sharing of ideas and a sharing of responsibilities, where a leader is a leader for the moment only, where the leadership exerted must be validated by the consent of followers, and where leadership lies in the struggles of a community to find meaning for itself. (Foster, 1989, p. 61)

Another perspective of leadership in the context of community and the common good is provided by Bryson and Crosby (1992) who inform us: 
We live in a world where no one is 'in charge.' No one organization or institution has the legitimacy . power, authority, or intelligence to act alone on important public issues and still make substantial headway against the problems that threaten us all.(p. xd)

Bryson and Crosby address the issue of leadership in modern society where complexity and rapid change are the rule.

In summary, culture and leadership are related. Leadership in creating change within an organization, or a group of organizations, requires an understanding of the culture(s) of those organizations. Culture, as the basic assumptions that underlie an organization's defining itself, is fundamental to its adaptability. Adaptability is necessary for coping with the external environment as well as reconciling internal integration issues.

\section{Cancer Prevention Empirical Data and Current Views}

Schopler's (1988) research provides historic perspective and portrays the current status of experience in the field. She reports that organization policy formulated by the National Cancer Institute entails coordination among the multiple and diverse specialty groups which are funded to conduct prevention research, and provide other related cancer services. She informs us that:

"Increasing attention given to inter-organizational relations in recent decades has ... led to identification of internal and external factors that appear to influence the adaptation and productivity of these systems over time" (Schopler. 1988, p. 17).

Proctor (1995) provides insights on the cancer problem, stating: "The tragedy is magnified by the fact that the causes of cancer are largely known and have been for some time" (p. 1). He refers to the environmental factors, nutrition, drinking water, occupational issues, genetics, and the "culture into which you're born" (p. 1). He poses certain questions that form the framework for his critical analysis. These questions relate to all scientific endeavor, but with application here to cancer policy. 
The three central questions Proctor (1995) poses are as follows:

1) Why do we know what we know, and why don't we know what we don't know?

2) Who gains from knowledge (or ignorance!) of a particular sort and who loses?

3) How might knowledge be different, and how should it be different? What are the virtues of looking at ultimate rather than proximate causes, for example, or of seeking prevention rather than cure? What are the social responsibilities of the cancer theorist or for that matter, of the science theorist? (pp. 8-9)

In the context of research priorities, Proctor presents the notion that the decisions on what to study, and what not to study are subjective, and may be influenced by subjectively created factors. The scientific community setting policy for cancer research funding may have the right intentions, but may be working within a cultural paradigm that inhibits the more optimum solution.

Soffa ( 1994) reports her experience as a breast cancer patient and advocate:

"Breast cancer is managed by the medical establishment with little presumption or hope that it can be prevented . . . novel research projects and adequate funding have been absent because of the lack of patient constituencies willing to put themselves on the line by speaking up for better treatment, for better understanding of the causes . . . and for prevention." (p. 5-8)

She states, however. that this old model is now being challenged. She bases this on the growing breast cancer advocacy movement that may at times be disorganized and lack consensus, but is heading in the right direction.

Singer and Grismaijer (1995) posit that "cancer is a disease of alienation" (p. 170). Their general hypothesis is that the root of the problem of cancer is societal alienation. Their specific hypothesis is that bras can cause breast cancer. They state that we are alienated from our bodies, our lifestyles. 
our environment, our culture. They ask: "What is our culture doing to our biology and environment" (p. 171)?

In a chapter titled "The Real Enemy," Singer and Grismaijer, 1995) share their frustration in not getting response from experts in the field:

We tried to notify experts about our findings. We wrote Dr. Sam Broder, Director of the National Cancer Institute. . . . We sent the same information to Kerrie Wilson, National Vice-President of the American Cancer Society: Dr. M. Wilson of the President's Cancer Panel; E. McGrath, exec director of the American Women's Medical Association; P. Ireland, president of the National Organization for Women; B. Dooley, Exec Director of the Women's Research and Education Institute: . . . None responded. Not even the women's groups. None. Whom can you irust when your culture is the biggest enemy of your health? (pp. 171-172)

Their experience illuminates the diversity and number of organizations involved in cancer issues. Singer and Grismaijer (1995) are commenting on the consistent lack of responsiveness within the cancer community, in spite of the diversity and number of organizations.

Zakarian (1996) states, "cancer as a public issue is awakening from its long sleep ..." (p. 20). She describes four major reasons for the awakening:

There is more than one choice of treatment for many forms of cancer. Patients are becoming educated to the importance of their involvement in the decision-making process. . . .

Delivery of health care services is changing. The public is losing control over choice of doctors at the same time that it is becoming aware of the need to have that flexibility. . . .

Medical advocacy is an idea whose time has come. A decade of forceful AIDS activism energized treatment activists in many other diseases who recognized that health has become politicized. . . .

The nature of cancer advocacy has changed. Until now, advances in 
cancer treatment have been driven by health or social work professionals seeking funds to discover the cure. For the first time, grassroots cancer organizations, with a larger agenda. are demanding

a voice in setting cancer policy and priorities. (p. 20) Zakarian (1996) makes a compelling case to inspire cancer patients to get the knowledge they need to become their "own expert" and turn their "personal advocacy into activism" (p. 21).

\section{Organizational Leadership in the Context of Cancer}

William Fishman. Ph.D. founder and president emeritus of the La Jolla Cancer Research Foundation, personifles the nature of leadership that has dominated the work of cancer research. The significance of his life work is that it is an example of how organizations have developed to address the cancer problem guided by certain leadership constructs: methods, styles, concepts. beliefs, culture.

The evolution of organizations that began with the War on Cancer in the 1970s, and continues today, is based largely on the leadership that dominated the era. Fishman is one of the pioneers that defined the organizations and the leadership that shaped present day cancer organizations. In his autobiography. Fishman (1995) describes the "Evolution of the Administrative Structure and Scientific Programs:"

Several principles guided us. One was to impose the very minimum of bureaucracy on the staff, to have the administration serve the scientists' needs. ... individual scientists were recruited with great attention being paid to their flelds of interest in order to match them with existing ones. . . . Our first putative program leader did not want to review grant applications . . . the Institute's prestige to submit only first-class applications was a secondary consideration to him. . . . His place was taken by Dr. Erkkd Ruoslahtl who was anxious to advance the field of extracellular matrix interactions. (pp 157-160) 
Fishman describes the components that made his organization successful, including: Fund-raising patron programs, building programs, and technology transfer. Significant in this autobiographic sketch is the emphasis on organizational development and leadership in the context of "building an organization." Significant as well is the lack of emphasis on accomplishments related to the eradication of cancer as a disease. The achievements are more in the realm of pushing the frontiers of science in cancer biology, rather than in finding the cause of a chronic disease.

In contrast to the organizational leadership of cancer scientists and executives is the leadership of cancer patients that have also formed organizations. Beverly Zakarian. co-founder of CAN ACT, has published her story. In the telling of her story as activist and cancer patient. it is an entirely different perspective from that of Fishman.

Zakarian (1996) describes all that is relevant to coping and surviving the disease through empowerment and education. She states:

Being empowered permits us to participate in our own important decisions with a sense of control, as well as actual control. Empowerment gives us the right to assume responsibilities for things that concern us. It enables us to act in our own interests, whether we are talking about cancer or doing something about it. (p. 20) She implies the need for leadership by invoking cancer patients to recognize their mutuality: "we are people with important interests in common" (p. 20).

Zakarian (1996) posits a concern she calls professional:

The people making policy decisions about cancer are doctors, researchers, and even technicians; oncology nurses and social workers; executives of drug companies and of health insurance companies; fundraisers and lobbyists. These are the people sitting on hospital boards, and pharmaceutical company boards, the board of the American Cancer Society, the boards of the hundreds of smaller fund-raising organizations. Is it any wonder there's no sense of urgency about your 
life or mine? (pp 192-193)

These two examples of leadership represent contrasting views of organizations that were formed with the intent of change and progress in cancer prevention. One is scientific, the other is grassroots advocacy. Theoretically they are both fighting battles in the same war -- a war that is aimed at cancer eradication.

\section{The Grand Scope: Larger Issues and Trends}

This section is a review of the literature that examines the larger trends and issues that affect the study population. These are the global or grand scope factors that impact the research activity area in subtle but powerful ways. Concepts such as community, worldview, and societal transformation are explored for their relevance in the study.

Lappe and Dubois (1994) provide an analysis of cultural and social issues in America today and propose political action via community organizations. They identify symptoms such as homelessness, failing schools, environmental devastation, and the federal deficit. They posit that the root of the crisis is society's inability to collaborate effectively: "we as a people don't know how to come together to solve these problems" (Lappe and Dubois, 1994. p. 9).

Gouillart and Kelly (1995) state:

It is time to replace our mechanistic view ... with a more organic one. and to endow the recently discovered biological nature of our corporations with a new spirituality that recognizes the sanctity of individual human life and has compassion for individuals (p. 4). Gamst (1995) offers the construct of a "web of rules" to describe the work relations in mechanistic industrial society and in the new shaping of postindustrial or postmodern organizations. He describes human work as a "sociocultural process encompassing organizations, laws, practices, and customs of work" (Gamst, 1995, p. 149). 
Bellah, Madsen. Sullivan, Swidler, and Tipton (1985) suggest a need to transform American culture and society. They inform us that a transformation would have to take place at a number of levels: "If it occurred only in the minds of individuals ... it would be powerless" (p. 286). They posit that personal transformation among large numbers of individuals is essential, but the transformation must involve not only raised consciousness but individual action. It is a notion of transitioning the human family to a new level of social integration, a "newly vital social ecology." Without it, "there may be very little future to think about at all" (p. 286).

These notions on a macro level relate to the need for new social technology, identified by Schopler (1988) in her dissertation on oncology organizations. The larger implications of these research findings involve the need for change in each member of an organization, as well as the collective, to find new ways for collaborative problem solving in order to confront the complex issues of society, issues such as cancer.

The concept of community is often noted as a social construction that will make it possible for transformation to be realized. A definition of community is offered by Shaffer and Anundsen (1993) as a:

. . . dynamic whole that emerges when a group of people:

participate in common practices; depend upon one another: make decisions together; identify themselves as part of something larger than the sum of their individual relationships; and commit themselves for the long term to their own, one another's, and the group's well being. (p. 10)

It is this sense of community that Cuomo (1995) heartens when he speaks of the creation and sustaining of American Democracy. He contends that we, as a society, are facing the same core questions that have always defined and shaped societies:

Who are we as a people? What ultimate values inform our individual souls? What values, if any, configure our soul as a nation? (p. 71) 
Cuomo places individualism and community in perspective with a discussion of what made America a great nation:

As we grew and industrialized, we continued to cherish the strength of our democracy, our spirit of initiative and personal drive, our sense of daring and capacity for innovation, but we recognized that if we limited ourselves to old-fashioned individualism, we would be limiting our nations's strength and our chance for progress. Seeing all this, we added one more powerful principle that subsumed all the others and that helped us create the most successful nation in world history: the idea of community .... (p. 72)

The idea of community in organizational cultures has been amplified in the Mondragon experiment. Foote Whyte and King Whyte (1988) describe a cooperative approach to organizational operations. They draw a distinction between ethnic culture and organization culture in stating:

... we recognize that the leaders of Mondragon have built a distinctive organizational culture and that we can better advance our understanding of Mondragon by analyzing this culture than by concentrating on the ethnic culture of the Basque people. (p. 254)

They define culture as a "system of widely shared beliefs and values and a set of characteristic behaviors used in organizing social processes." They continue with: "The culture includes an ideology, a cognitive map, or framework within which people explain their own characteristics and their relations to others of different cultures."

It may be difficult for many organizations to meet these criteria. But in not developing shared values and mutuality skills, many complex mutual coendeavors involving multiple organizations may not succeed. The creation of the American democracy, and the success of Mondragon are two examples of community values contributing to societal growth and progress.

Some authors have addressed the need for change from a worldview perspective with implications for cultural transformation. Harman (1988) 
states:

Each of us holds some set of beliefs with which we conceptualize our experience -- beliefs about history, beliefs about things, beliefs about the future, about what is to be valued, or about what one ought to do. What may be less obvious is that we have unconscious beliefs as well as conscious ones. (p. 14)

Mollner (1992) defined two fundamental worldviews: a material age, and a relationship age worldview. The material age worldview is based on the belief that the universe is composed of separate parts competing for self interest. The relationship worldview is based on the belief that the universe is composed of "connected parts, each of which cooperates with all other parts in the interest of the universe first and only secondly cooperates or competes in the interest of itself or any sub-group of parts" (p. 97).

In summary, there are cultural and sociological issues and trends of a global scope that influence the nature of organizations. Cancer organizations are not exempt from these issues and trends. Issues such as the globalization of business enterprise, and trends such as coalition building to address complexity also impact cancer organizations.

Organizations, at all levels and complexity, are challenged with the need to collaborate and form coalitions with other organizations that are adapting to a rapidly changing global society. One may theorize that out of this change will emerge new organization structures and forms that will facilitate solutions to the complex issues of society. 
BCP Culture/Leadership

\section{Chapter III: Research Design and Methodology}

\section{Introduction}

The design and methodology section outlines the research process and the specific options taken to satisfy the purpose and goals of the study. The study aim was to develop an understanding of the interrelationships and dynamics within, between, and among the various arenas and organizations that collectively represent the study activity context.

The data were collected from interviews with participants representing different arenas and organizations, a focus group interaction, observations at conferences and seminars in which information was shared, and written materials communicating information relating to the study.

Figure III- 1 depicts the steps in the research process. The researcher first posed general research questions and developed an interview guide. Data collection then commenced. followed after each interview with analysis to define/code categories. Memos were documented during the analysis to capture work-in-process ideas and concepts. After completion of the interviews, the formal write-up began to describe the findings based on the discovery process.

Chapter IV describes organization culture categories and connections emergent from the data. This chapter responds to the research questions posed in this study relating to the nature/types of cultures uncovered, and the relationships between cultures and prevention policy. Chapter $\mathrm{V}$ expands on the major categories of organization culture and leadership, with examples from the data of clashing cultures and collaborative networks. Also included are examples of leadership expression linked to culture based interpretations. Chapter VI develops theory related to cultures observed, namely -- the interaction of breast cancer advocacy with the conventional wisdom of cancer prevention. Chapter VII provides the perspective of the researcher which includes a key metaphor percelved from the data. 
BCP Culture/Leadership

\section{Methodology Overview}

The research conducted was naturalistic and qualitative. It sought to collect, document, codify, analyze, and make meaning of the perceptions of individuals that have experience as employees or volunteers in the study activity context of breast cancer prevention. The focus was on the phenomenon of organizational interaction within various arenas of breast cancer prevention. The arenas that were the main focus of the research are the three principal prevention strategies employed in cancer work: primary, secondary, and tertiary prevention.

The methodology chosen for the study was a blend of: (a) grounded theory (Schatzman, Strauss 1973), (Strauss, 1987), (b) interpretation (Schatzman. Strauss 1973), (Wolcott, 1994), and (c) I-witnessing (Wolcott. 1994). Grounded theory is a qualitative methodology that builds theory inductively from the phenomenon it represents. The approach is designed to generate the discovery and conceptualization of complex interactional processes. Theory that is "grounded" is discovered, developed, and provisionally verified through systematic data collection and analysis of data pertaining to that phenomenon. "One does not begin with a theory, then prove it. Rather. one begins with an area of study and what is relevant to that area is allowed to emerge" (Strauss \& Corbin. 1990, p. 23). Therefore, this study identified an activity context and allowed what was relevant to the organizational interaction, within the activity context, to emerge.

Characteristics of grounded theory that were incorporated into the study include: (a) inductive, (b) interpretive, (c) discovery oriented, (d) emergent, and (e) theme focused. The emphasis is on interpreting the data to discover inductively that which provides symbolic meaning for organizations and individuals expressing culture within the study activity context. 


\section{Study Activity Context}

The activity context for this study was the intersection of three activity elements: (a) cancer prevention strategy. (b) breast cancer advocacy, and (c) organization culture. Figure III-2 portrays the intersecting of these three separate elements to create a new combined study activity context. The research involves organization culture in the context of cancer prevention strategy where breast cancer advocacy has been introduced as new organizational phenomenon. This combined activity context is called in this study: the breast cancer prevention (BCP) community (or metaorganization).

This study initlally identified six arenas in the BCP community: (a) primary prevention, (b) secondary prevention, (c) tertiary prevention, (d) information support, (e) funding, and (f) advocacy. Each arena was hypothesized to exhibit values and beliefs that affect the nature of policy shaping within. between. and among organizations in the BCP community. As the study unfolded, the main focus became the three prevention arenas and the advocacy arena. The remaining arenas (information support and funding) were not significant in the study based on. or grounded by, the interview data. Therefore. they were not included in the analysis and interpretation.

Primary prevention is considered in this study to be cancer prevention aimed at uncovering the cause of the disease, and thereby eliminating the incidence of cancer. Secondary prevention is considered in this study to be cancer prevention aimed at reducing the mortality of the disease usually through a physical intervention, such as surgery or mammography. Tertiary prevention is considered in this study to be cancer prevention aimed at reducing incidence and mortality through education and counseling. Collectively, they represent key arenas in the study activity context that interact with breast cancer advocacy. 
BCP Culture/Leadership

\section{Research Design}

\section{Data Collection}

Entre was accomplished through professional and personal contacts, and from meeting participants at conferences. Participants were selected based on their arena representation, and satisfying the criteria of having worked or volunteered in cancer prevention directly or indirectly for at least one year. The goal. that was achieved. was to have representation from all the arenas of primary, secondary, tertiary, and breast cancer advocacy.

The data were collected from the following sources: twenty-four semistructured one-on-one interviews with sixteen participants, including two from the European research community, over a period of ten months; a focus group of six participants (four who were one-on-one also); a press conference; an education conference: an alternative medicine symposium: reports, articles. memos, and other documentation relating to cancer prevention.

The one-on-one interviews consisted of an initial interview (in person and/or telephone) with sixteen participants that represent different arenas, and eight followup interviews with the same group. The followup interviews were focused on new questions that emerged from the analysis and validations on findings.

The focus group data consists of a four-hour discussion by six participants representing four arenas. The researcher asked each participant to share their experience in cancer prevention with the group. The participants were: a breast cancer activist and founder of the Breast Cancer Action Group (BCAG); a writer and board member of BCAG; two cancer researchers; the Director of the Naval Health Research Center, and; a board member/activist of the American Cancer Society. Each of the participants in the focus group were also interviewed in the one-on-one format. The purpose of the focus group was to collect data in a 
group setting consisting of participants of diverse arenas.

The press conference was conducted by the American Cancer Society (ACS), and co-sponsored by the National Cancer Institute (NCI) and the Centers for Disease Control/Prevention (CDCP). One purpose of the press conference was to present findings from a study by the University of Alabama. Another purpose was to initiate a collaborative process among the major organizations represented.

The education seminar was sponsored by the San Diego based Y-ME organization and the Women's Cancer Task Force. Four researchers made presentations: three specializing in basic research, one in information support. The purpose of the seminar was to inform participants on current breast cancer research.

The alternative medicine symposium was attended by the researcher and two participants of the focus group. The purpose of the symposium was to share information and experience relating to the application of alternative or holistic approaches to healing.

The reports and documents ranged from official reports from the federal government to informal memos stating policy on cancer prevention by activist groups. An example of an official report of strategic significance is the National Strategic Plan for the Early Detection and Control of Breast and Cervical Cancers.

Saturation was reached after eleven interviews. This was based on the researcher's judgement that interviews twelve through sixteen, as well as followup interviews. did not yield new categories outside the framework of the analysis. New data from each interview were compared with existing categories and themes defined. The categories and themes stabilized after the eleventh. 


\section{Interviews}

Twenty-four interviews were conducted with sixteen participants from organizations representative of the arenas. The criteria for selection of participants was that they had held a position in an organization, or served within one of the arenas, for at least one year. Eight of sixteen participants participated in a follow-up interview.

Data were collected through taped interviews, and then transcribed to hardcopy for memoing and coding. Memoing in the form of observational, theoretical, and methodological notes was employed in the recording and documenting of the process. The study followed ethical procedures involving confidentiality and protection of human subjects. After I completed all transcripts, I destroyed the tapes.

The following questions guided the first interview:

1. Would you describe your position with the organization?

2. How does your organization fit within the breast cancer prevention community?

3. Could you describe your relationships with other organizations that collaborate in your work?

4. How do you communicate with these organizations?

5. What is the nature of the interaction with organizations that would be included within the BCP community?

6. Could you describe how these organizations are grouped?

7. What are the values, beliefs that are shared (not shared) in the BCP community?

8. How are these shared values and beliefs expressed by the community?

9. How are goals and policy that guide action formed?

10. Could you describe the informal structures and relationships that you have experienced?

The following questions guided the follow-up interview: 
1. The following cultures emerged from the first interviews. Would you comment on them?

2. The issues of collaboration and leadership emerged from the first interviews. Would you comment on your views of these issues?

\section{Protection of Human Subjects}

The participants were given consent forms prior to being interviewed. They read and signed the informed consent form as per the guidelines in the Doctoral Handbook (1995) published by the School of Education. University of San Diego. A copy of this form is contained in Appendix B. Approval by the committee on the protection of human subjects was obtained.

The participants and/or the organizations involved were not at risk beyond normal fatigue experienced in an interview. Anonymity was maintained by using fictitious names. Interviews were taped, and the tapes were destroyed at the end of the study.

\section{Data Analysis}

\section{Overview}

The analysis applied grounded theory to uncover categories from the data. The results of this analysis which includes organization culture categories, and connections between the categories, is in chapter IV. Key categories emerged from the discovery process. These key categories are explicated in chapter $\mathrm{V}$ with illustrative examples from the data. The analysis also uncovered a special interaction between the dominant organization culture and the breast cancer advocacy movement. This interaction involved a complex series of processes, a time dimension, and turning point outcomes. This is described in chapter VI.

In addition to Schatzman and Strauss (1973), and Strauss (1987), the 
BCP Culture/Leadership

analysis was guided by the following objectives or purposes of grounded theory (GT):

1. To study fundamental patterns known as basic social-psychological processes which account for variation in interaction around a phenomenon or problem (Chenitz \& Swanson, 1986).

2. To discover and conceptualize the essence of complex interactional processes (Hutchinson, 1986); where process has a time dimension. stages, and turning points (Fagerhaugh, 1986).

3. To generate theory about social and psychological phenomena (Chenitz \& Swanson, 1986). GT attempts to build theory "from the ground up," theory "grounded in the lived experience of the subjects (Hutchinson, 1986) (Bowers, 1988). Grounded theory does not just report on or give voice to what is heard, but also interprets what is observed. heard, or read (Strauss \& Corbin 1994).

Grounded theorists believe that research should focus on how people view their circumstances, how they interact. and how these processes change (Wilson $\&$ Hutchinson, 1991). The meaning of the event or phenomenon must be understood from the perspective of the participants (Chenitz \& Swanson. 1986).

\section{Applied Methodology}

The applied methodology for analysis followed most closely the approach to "discover and conceptualize the essence of complex interactional processes" (Hutchinson, 1986). Diverse organizational cultures and connections between cultures were discovered from conceptualizing the complex interaction of the organizations studied. Observed were interactions where complex processes had a time dimension, stages, and turning points (Fagerhaugh, 1986).

An example of complex processes with a time dimension and stages was the interaction between the breast cancer advocacy movement of the 1990 s and the conventional wisdom culture. Emergent from the data was a time dimension 
with stages representing the collision of the cultures and the resulting outcomes. Also. there was a turning point in which advocacy experienced changes in its cultural identity. The breast cancer advocacy movement, and the outcomes generated by the movement. had time dimensions and turning points. Therefore, grounded theory was applied to the processes experienced by breast cancer advocacy as it interacted with the conventional wisdom in cancer prevention. generating a turning point in the advocacy movement.

Finally, the perspective of the researcher was added to provide a personalized connection. The researcher's four years as a cancer registry director and three years as a breast cancer activist met the criteria imposed in the study for participation. This method was guided by I-witnessing methodology (Wolcott. 1994). A key linkage or metaphor was sought by the researcher that integrated the unique perspectives of the participants.

\section{Summary}

Twenty-four interviews were conducted with analysis guided by a blending of grounded theory procedures, refocus on interpretation. and I-witnessing. Coding of the data to uncover categories began after the first interview, initiating an iterative (or concomitant) approach to data collection and analysis. Each new interview provided new data to code and contrast against existing data. The results / findings and discussion followed the analysis. Further analysis (a return to the data) was necessary during the crafting and write-up process. The research was naturalistic and qualitative to develop grounded theory relating to workers and volunteers participating in different arenas within the breast cancer prevention community. 
BCP Culture/Leadership

\section{Chapter IV: Cultures: Descriptions and Connections}

\section{Introduction}

This chapter includes the following: (a) summary of findings; (b) culture descriptions: (c) organizational formal connections; (d) support connections; and (e) cultural actors and crossovers. The organization culture descriptions are followed by a discussion of the connections observed between cultures and the phenomenon of crossover actors.

\section{Summary of Findings}

The findings from the study are summarized as follows:

1. The breast cancer prevention community is made up of diverse organizations that appear to serve in six arenas as defined in chapter one. Three of the arenas represent prevention policy strategies: primary, secondary, and tertiary. The three other arenas represent: organizations/individuals that provide information support (arena 4), organizations that perform funding activities (arena 5), and organizations/individuals that perform advocacy (arena 6). Certain organizations and individuals represented in the study appear to conduct activity in more than one arena. Therefore, mutual exclusivity did not appear to exist related to arena involvement. Definitions of the arenas are provided in Chapter One.

2. The participants from the six arenas that were interviewed or observed seem to have unique perspectives on the efficacy of prevention policy and practice. The unique perspectives reflect different cultures that in the majority of cases observed, appear to be in conflict relative to the conduct of research and prevention strategies.

3) The following cultures emerged from the interviews:

(a) business, (b) clinical medicine, (c) patient care, (d) conventional wisdom, (e) 
radical activism, (f) political activism. (g) outreacher, (h) holistic, and (i) research idealism.

4. The diverse cultures appear to spawn cultural "actors." These are key individuals who speak, act, and initiate policy positions within arenas sampled. The actors are observed to represent, on occasion, more than one culture. Observed was a phenomenon that is described by this research as a "crossover." The crossover actor is one that takes on a hybrid cultural character. The hybrid or crossover actor has characteristics of multiple cultures. The medical practitioner who is appointed to an executive position is an example. As an executive, the physician must practice business methods as well as medical procedures. Therefore, the executive-practitioner works in both cultures.

5. The arenas and cultures observed exhibited relationships or "connections." Connections are the special types of relationships between and among organizations and individuals that were found to be formal and informal. The formal connections are the relationships formed by organization charters. The support connections take a different form. interrelating arenas and cultures, and emerge as possibly presenting the more meaningful connections. The support connections represent alignments in ideology and belief systems. Figure IV-1 relates the nine cultures and the six arenas observed in the study. The connections are of a formal or mission-oriented organizational nature.

6) The existence of collaborating networks was observed in various settings. A collaborative network was an observed condition/action process in which individuals or organizations were engaged in a cooperative effort to achieve a shared vision or goal. The data suggest, however, that clashing (differences in belief systems) was more reflective of the interaction between cultures.

7) The majority of participants agreed that cancer prevention activities transcend organizational boundaries, and include many diverse entities from different arenas. However, at issue was the characterization of these diverse 
organizations as representing a true community or a metaorganization. Metaorganization appears to be more appropriate due to the observed lack of cohesiveness among arenas.

\section{Cultural Descriptions}

The business culture was defined as the culture of "economic pragmatism" by a participant. The philosophy underlying this culture is the belief that all elements of an organizational entity should contribute to the financial health of the total organization. Therefore, all elements are evaluated based on their potential to create financial gains - turning cost centers into profit centers. The business culture is invested in secondary prevention based on the profit potential inherent in that arena. Mammography, for example, is an area of secondary prevention that can be a profit center for the health care providers and manufacturers of the equipment.

The business culture is also involved in information creation and dissemination that would be utilized to plan for services. For example, information on the number of breast cancer cases predicted for a geographic area would enable the business planner to define the market for services such as mammography. As one participant related:

This can have both good and bad outcomes. Its good to be organized and market oriented, but when that goes too far, the welfare of the patient is at risk.

Another participant stated:

The business culture has moved into the health arena. Medicine has become a for-profit operation: the real money is being made by HMOs and insurance companies. Who is setting the policy, driving - steering the wheel in this direction? Its an avalanche.

Clinical medicine (CM) was observed as the culture of medical care 
institutions. It is the classic model of health care practiced in most hospitals and clinics. This culture practices rigid, clearly defined beliefs and methods in the conduct of the medical professions, and in their relationships with patients. The beliefs include that patients will benefit best by the pre-ordained methodology that has served the classic medical model. It is characterized by "the physician knows what is best for the patient, and the patient should comply." Clinical medicine is heavlly invested in secondary prevention: prevention through administering treatments that reduce mortality.

A participant had the following to say about clinical medicine (CM):

They $(\mathrm{CM})$ are slow to embrace sharing. The idea of inter-institution collaboration is not working. Physicians are threatened by change. They want to keep their 'products' to themselves -- their patients. that is.

This participant's perspective is that clinical medicine has not embraced the business culture sufficiently. He believes that good business practice will ensure continued success.

They (the institution) still have the mind set of: "we need to spend $\$ 3000$ by the end of the year to justify our budget."

In the opinion of the participant, this policy has contributed to the institution's financial shortfall. In contrast to this example, many health care institutions have embraced the business culture to be competitive and survive financially.

An article in the Atlantic Monthly. titled Good News and Bad News about Breast Cancer by David Plotkin. M.D., defends the case for clinical medicine. The basic rationale is that the medical profession is doing all it can possibly do, and that "all" is not as bad as it is portrayed by activists and the media. Plotkin states:

If the improvements in women's lives have indirectly promoted breast 
cancer, then it is unhelpful to call the growth in its incidence an epidemic. In medical terms, an epidemic is the sudden outbreak of a generally rare condition, such as the deadly spread of cholera in a city with contaminated water, and should be stopped by striking at its source. Unfortunately the enormous publicity accorded the rise in breast cancer incidence has obscured the fact that the disease is not the leading killer of women.

He defends claims by the medical profession with:

... the increase in cures precisely canceled out the increase in incidence, leaving the overall death rate unaffected. When my colleagues claim that we are curing breast cancer, they are implicitly endorsing this view. And why not? . . a smaller percentage of their patients are dying. (June, 1996, p. 58-60)

The focus of clinical medicine, as characterized by Plotkin, is on the treatment of the disease. And although the terms "prevent" and "cure" are applied, they mean the prevention of death -- which is secondary prevention -not the prevention of the disease as a complete cure (or eradication), which would be primary prevention. Plotkin's case is typical of the belief system shared by the clinical medicine culture. It sincerely believes that it is doing well in serving the clinical needs of patients. Their training is in providing treatment protocols (secondary prevention), and therefore, their practice is focused on secondary prevention.

Patient care is the culture created and now embodied by the American Cancer Society (ACS). It is a culture of believing that the patient needs support through the crisis of cancer, and that healthcare should cooperate in providing support that extends beyond the primary treatment such as surgery. The patient care culture is a proponent of early detection through mammography, which is secondary prevention. 
The ACS has adopted early detection as a pragmatic approach to decreasing mortality. It is based on the belief that if the tumor is detected early through mammograms, then the patient has an increased chance of survival. Survival data does not validate this belief, but their policy is based on the belief that the patient's care and survival is paramount.

Conventional wisdom embraces parts of what is found in the first three cultures defined. A fourth dominant element that characterizes this culture is "good science." Good science is about following scientific methods and quantitative models that are considered proven and accepted by the scientific community, and that involve little or no risk. This culture is embodied in the National Cancer Institute (NCI), but also permeates most of the old line cancer worker community internationally -- especially the cancer information registries. This is a culture that depends on peer review as the decision and approval model to determine who gets the resources. It is considered to be the dominant culture by the majority of participants, based on its power resources in funding and influence. A participant stated:

Because of the complexity of society, we now need science. Science is king.

Radical activism is the culture that emerged from the discontent of breast cancer victims (patients and their families) and the urgency created by alarming incidence and mortality rates. It is outside the scope of this study to conjecture why this culture, which some describe as a social movement, took place. The culture was described in the words of a participant as, "impatient" and "wanting answers now." Inspired by AIDS activism, this group became visible and provoked their political representatives to initiate legislation. They were successful in increasing the levels of breast cancer research funding, and by taking the disease out of the closet and onto the covers of magazines. Never 
before had women such as fashion models "bared their chests" to expose the experience of breast cancer. They wanted to be known, accepted, and even admired for their courage and integrity. They were successful as a movement to change public opinion and funding policy.

However, as the movement matured, the social dynamics resulted in power issues. One activist participant shared that, "it became a contest to see who would become the big chief."

Radical activism is involved in arenas 3 and 6 (tertiary prevention and advocacy). An article that appeared in the January, 1991 issue of Time magazine described the launching of the activist movement:

In recent years a ground swell of breast cancer victims, feminists and legislators, inspired by the success of the AIDS lobby in bringing attention and funds to that epidemic. have been pushing for better regulation of mammography standards, for mandatory insurance coverage of mammograms, and generally for more research into the still mysterious roots of breast cancer. They point out that the US government spends only $\$ 77$ million a year investigating ways to prevent the illness, against $\$ 648$ billion on heart-disease prevention. (p. 52. Reported by J. Madeleine Nash/Chicago and James Willwerth/L.A.)

Out of pure activism, that was initially radical in nature, came another form of advocacy: Political activism. This culture believes that radical change is not feasible because it threatens the conventional wisdom. Therefore, the stance or policy position of this culture is that of more moderate change aligned with the ongoing established policies espoused by the conventional wisdom. Political activism is more actively involved with information support and funding as well as advocacy. This culture has not aligned itself with the alternative medicine approach (arena 3).

Political advocacy embraces different more aggressive strategies for fundraising. An example of the state of the art in fund-raising within this cultural 
arena is an event sponsored by the Susan Komen Breast Cancer Foundation. An article in the New York Times Magazine (December 1996) titled How Breast Cancer Became this Year's Cause included the following:

The 2100 guests at the Susan G. Komen's Breast Cancer Foundation's charity gala in Dallas in October expected a luncheon. What they got was an extravaganza. . . . A bit much? Perhaps. But all part of what it takes to become the cause in the competitive world of causes; to remain the disease in an era when everyone, particularly during this season of giving, is trying to get attention for his or her disease.

The thrust of political advocacy is influence and power, in contrast to grassroots activism which is about changing the consciousness of victims and society.

The outreacher culture was identified and described by a veteran patient care culture executive. The outreacher, according to the participant, is either a cancer patient, friend, or family member that has been touched by the disease; that wants to help other cancer victims, but then desires to return to their "normal" lives. This differentiates them from activists. They are active only during the outreach and in a nonvisible manner. They do not share the passion to make radical change or create political influence. The arena involvement is secondary and tertiary prevention, as well as the dissemination of information to support cancer victims.

The three cultures, radical activism, political activism, and outreacher, are relatively new to the cancer prevention community. Ten years ago, they did not exist -- not in the forms they do today. This is in contrast to the previously described cultures that have been in their current forms for at least twenty years. However, in a relatively short period of time, their influence has been effective to create change.

The holistic culture was identified by a participant from the tertiary prevention arena, an oncology social worker who used the term to characterize the world of alternative medicine. It is growing and becoming more accepted by 
the mainstream medical community. Also referred to as complementary medicine. this includes a wide range of healing and support methodology from counseling to spiritual healing. In the context of this research, this is a culture that is embraced by other cultures discussed, namely, radical activism and outreacher. The arena functional activity is limited to tertiary prevention.

The holistic culture is exemplified in the mission statement of the Planetree organization taken from the proceedings of the first Alternative Therapies Symposium (January, 1996):

Our mission is to create healthcare environments that support and nurture healing on all levels -- physical, mental, emotional, and spiritual. Planetree encourages consumers to become active participants in decisions relating to their treatment and care. (Proceedings, p. 11)

The diverse nature of the cultures is described in a statement from the Symposium proceedings by Larry Dossey. M.D.: "Perhaps the primary characteristic that distinguishes alternative and conventional therapies is the role accorded to mind or consciousness" (p. 45. Proceedings from Alternative Therapies Symposium. January, 1996). The reference to "conventional therapies" would be considered the clinical medicine and conventional wisdom cultures as they are defined in this study.

Dossey (1993) relates his experience in discovering scientific studies supporting the power of prayer. His experience provides a contrast between the holistic and clinical medicine cultures. but beyond that, provides insight into the influence of conventional wisdom on all cultures:

I found an enormous body of evidence: over one hundred experiments exhibiting the criteria of "good science," many conducted under stringent laboratory conditions, over half of which showed that prayer brings about significant changes in a varlety of living beings. . . I came to realize the truth of what many historians of science have described: A body of knowledge that does not fit with prevailing ideas can be ignored as if it 
does not exist, no matter how scientifically valid it may be. (p. xv) The "prevailing ideas" referred to here by Dossey is the conventional wisdom culture in the context of this study. This is an example of the belief by certain participants that conventional wisdom, as the dominant culture, guides the decision making and policy shaping within the metaorganization that includes cancer prevention organizations.

Lastly, the culture that conducts primary prevention is researcher idealism. This culture, consisting mainly of epidemiologists, believe that the cause of cancer could be found if a coordinated, dedicated, and funded attack were launched. It is their belief, however, that other cultures, most significantly conventional wisdom, no longer believe that cancer can be conquered. Research idealism believes that conventional wisdom contains a credo that cancer is a permanent condition in society, and therefore must be endured. Implicit in conventional wisdom according to the researcher idealist, is the obligation of society to support cancer organizations in order for them to sustain the ongoing, never-ending battle.

\section{Organizational Connections}

All cultures observed in the study were found to have relationships or connections to the three prevention arenas (primary, secondary and tertiary). Two types of connections were observed: the formal/functional connection, and the informal/support connection. The functional connection is a formal organizational relationship. The support connection is an informal relationship that is formed by shared values, beliefs, and ideology. Figure IV-1 provides a matrix interrelating six arenas with the cultures that were found to be formally connected with. Figures IV-2 and IV-3 portray the informal support connections. The following is a description of the formal connections.

Primary prevention is conducted by the conventional wisdom and researcher idealism cultures. An example of conventional wisdom is the 
National Cancer Institute (NCI) that includes primary prevention in its official funding solicitations. Primary prevention is conducted by the researcher idealism culture observed.

Secondary prevention was observed to have formal connections that included the following cultures: business, patient care, clinical medicine, conventional wisdom, and outreacher.

Tertiary prevention was found to be formally connected to the clinical medicine, outreacher, and holistic cultures. Clinical medicine typically will house an oncology social worker to counsel patients. Outreachers are often assigned as volunteers to this arena. The holistic culture is dedicated to education and healing through counseling.

The information support arena appeared to have formal connections with: business, patient care, conventional wisdom, radical activism, political activism, and outreachers. This was not surprising in view of the renewed focus on education and empowerment of consumers to have information to assist in decision making.

The funding arena is formally connected, as would be expected, to those cultures that are chartered to fund projects. Examples are: conventional wisdom, business, and patient care to a lesser extent.

Lastly, the advocacy arena is formally connected to radical activism. outreacher, and political activism. These cultures born from advocacy would include salaried staff or volunteer workers.

In summary, the connections are the formal organizational relationships between individuals and their jobs that place them in a certain arena. $A$ formal connection most likely represents an organizational setting in which a member of the culture is employed or volunteered for service.

The functional grouping is in contrast with the next category that also represents connections. But these connections are informal and ideology-based. The next category of relationships among organizations and arenas are 
BCP Culture/Leadership

connected not by organization charts, but by shared policy beliefs that form informal relationships.

\section{Informal Support Connections}

Figures IV-2 and IV-3 portray informal support connections. These connections are observed as supporting based on the beliefs and attitudes expressed by participants grounded in the data. This is in contrast to the formal connections dictated by organization charts and mission statements. Figure IV-2 provides the culture connections to primary, secondary and tertiary prevention. Figure IV-3 provides the culture connections to advocacy.

Radical activism and research idealism support the notion that primary prevention is still possible. Therefore, both cultures support the policy of increased resources for primary prevention. Radical activism is symbolized by the breast cancer patient who takes an active and aggressive role in changing the current belief systems and policy dictates which are maintained by the dominant culture (conventional wisdom). These are the front-lines who attack the low funding levels for breast cancer, and who question the allocation of resources. They want answers now. It is life or death for them. They are the creators of organizations such as Y-ME and ONE in NINE. They are for the eradication of cancer, and therein is their support link to research idealism.

Both cultures, radical activism and researcher idealism, share the belief that eradication is possible. This common vision aligns these two cultures. The researchers tend to be epidemiologists -- researchers that study disease in the population with the ultimate goal of finding the cause. Diseases such as cholera, small pox. and pellagra were eradicated through the work of epidemiologists. Radical activists and research idealists share the belief that other cultures, dominated by conventional wisdom, "have given up" on primary prevention. The conventional wisdom, according to three of the researcher participants, is to invest in studies that will yield in the short term vis-a-vis 
BCP Culture/Leadership

secondary prevention.

Secondary prevention is supported by the following cultures: patient care. outreachers, business, political activism, clinical medicine, and conventional wisdom. Each of these cultures has arrived at this stance or belief paradigm for differing rationales. This paradigm is based on the belief that the greatest return on invested resources will be derived by focusing on decreasing mortality. This is in ardent contrast to those that support primary prevention, where eradication of incidence is the goal.

From the data. there does not appear to be a mutuality or collegiality between these two groups (primary and secondary). Each believes they are on the right course. The environment is not one of complementary collegiality or cooperation, but competition. The solution from each perspective can be characterized as mutual exclusivity, as compared to cooperative inclusivity.

Clinical medicine supports secondary prevention because it fits the classic healthcare model that treats the cancer with medical intervention (surgery, radiation, chemotherapy) to decrease the probability of mortality. New approaches embraced by managed care systems that support non-invasive prevention methods are somewhat threatening to this group.

The patient care model has been adopted by cultures such as the American Cancer Society and outreachers, based on the philosophy that deceasing mortality can make a difference "today" in the life of a cancer victim. This is the rationale for major resources and energy being expended in the area of early detection. Early detection prevention is definable and doable. Therefore, these cultures believe they can help the patient best in this arena.

The business culture has also adopted secondary prevention. but for a different rationale. Here the rationale is based on the question: What will bring the greatest return on investment? The answer consistent with the business profit model is to treat patients with procedures that can be billed at a profit. This is the same business model that would apply to any profit oriented 
endeavor.

Tertiary prevention is supported by radical activism and outreacher cultures. Tertiary prevention does not address incidence or mortality directly. The strategy is based on the belief that counseling and education can lessen the impact of the disease, and possibly prevent mortality if intervention is early in the process. The professionals involved in this arena are typically oncology social workers.

There is another dimension evolving out of this arena that is given various names: alternative medicine, complementary medicine, holistic therapy, and/or spiritual healing. The researcher has chosen to call this culture holistic. This is a culture that is growing rapidly based on the membership statistics quoted at a first international conference held in January. 1996, titled: Creating Integrated Healthcare.

Two participants in this research representing the radical activism and outreacher cultures have become active in alternative medicine. They have integrated holistic culture as a tertiary strategy in a program for cancer victims called: Healing Legacies. This consists of combining art and education to inform and transform individuals that are impacted by the disease. The hope is that this approach will not only help those recovering from the physical and emotional scars, but also reach out to those who are at risk. In reducing the impact of the disease by providing education and counseling, tertiary prevention has a defined role as a prevention strategy.

Figure IV-3 portrays the informal connections to breast cancer advocacy. A distinction is made here between advocacy as a social movement/action arena and the cultures that were created by advocacy. As has been stated, three cultures were an outgrowth of advocacy: radical activism, political activism, and outreacher. Portrayed in this figure is that all three continue to support advocacy. Joining them are patient care and research idealism, observed from the data. grounded in the participant perspectives. 


\section{Cultural Actors and Crossovers}

Cultures observed in the study have individuals that play dominant roles in the development and sustaining of the culture, as noted earlier. These dominant role players are called "actors" in this study. Furthermore, the study resulted in defining actors that were hybrids of two different cultures. These are called crossover actors in this study.

The following crossover actor categories were found: executive practitioner, executive researcher, holistic activist, conventional wisdom researcher, conventional wisdom advocate, patient care executive. The variations developing from the crossover combinations contribute to the complexity of the cancer prevention arenas as well as to the whole cancer community.

The executive practitioner is an actor that dominates the business and clinical medicine cultures. These cultures come together in the example of one participant who is clinical director of a medical clinic. The participant follows the rules and dictates of clinical medicine in treating patients. but is aware of the business acumen necessary to survive in the changing environment of managed care. Therefore, both cultures are enacted in the practice of the profession of caring for patients. The participant stated:

Medicine is in a crisis situation. We have had reform with a small ' $r$.' We must convert to being an HMO, and deal with all the financial headaches now on top of the medical issues.

An exec. researcher participant shared how he must balance the research conducted with the constant need to justify his organization's existence. He splits his time between presentations in Washington to report work accomplished, and conducting "good science" research.

A holistic activist participant has moved from radical activism to the healing arts. She was a leader in the movement to get breast cancer more 
visibility vis-a-vis increased funding. As she describes, the movement evolved to a point where the dynamic changed from unified action against the establishment to different form. In the evolved form. the movement began to fragment: one faction became more political; another faction became more patient and outreacher oriented; still another remained radical to create change. The participant that remained radical became discouraged and ultimately found another medium to express her activism. This medium is the healing arts, which consists of integrating the experience and the expression of cancer victims in the medium of art. One such exhibit in a museum was called: Healing Legacies.

The executive-patient care participant has moved up through the ranks of a national organization that combines fundraising and patient support services. $\mathrm{He}$ is very active in early detection initiatives. In this secondary prevention mode, he finds he must collaborate with business and clinical medicine. All three of these cultures support early detection policy, but for different reasons. His motivation as a key actor of patient care, is not profit. He believes strongly that early detection will save lives.

\section{Summary}

The data present perspectives from participants in various organizational milieus of cancer prevention. The perspectives appear to be culture based, and therefore are grouped as nine distinct organization cultures. The cultures observed are: business, clinical medicine, patient care, conventional wisdom, researcher idealism, holistic, radical activism, political activism, and outreacher. Furthermore, these cultures appear to have linkages, or alignments, between and among diverse organizations. These linkages are observed to influence policy in support of primary/secondary/tertiary prevention strategies. Each culture appears to be aligned with one or more prevention strategies. 
BCP Culture/Leadership

\section{Chapter v: Clashing Cultures, Collaborations, and Leadership}

\section{Introduction}

This chapter addresses three key categorles or themes emergent from the data: clashing cultures, collaborating networks, and leadership. The data from interviews provide examples of the three themes observed. The clashing cultures are based on observed differences in policy regarding primary. secondary, and/or tertiary prevention: or relating to how information is collected/utilized, how funding is conducted, or how advocacy is pursued. The collaborating networks are based on observed cooperation and shared vision. Data from the study related to leadership expression are linked to leadership theory to understand the nature of leadership in the activity area/context. The discussion concludes with a synthesis of organization culture, culture survival, and leadership. Four examples were selected from the data for each of the three themes.

\section{Clashing Cultures}

\section{Research Idealism vs Conventional Wisdom}

Clashing cultures were evident from many of the interviews with participants. An example of conflict between a researcher representing research idealism and a researcher representing conventional wisdom is the following.

Dr. B and Dr. G, had conflict in their belief regarding the efficacy of primary prevention. Dr. B (conventional wisdom) was of the belief that primary prevention was not a feasible endeavor to be included with the other prevention strategies. This perspective clashes with researcher Dr. G. (research idealism) who reported a perspective that primary prevention can result in cancer eradication. Primary prevention advocates believe that their lack of success in 
finding the cause of cancer is due to inadequate funding for long-term epidemiologic studies.

The researcher participant. Dr. B, questioning the feasibility of primary prevention due to control group issues, and the nature of migrant populations that create difficulty for primary prevention studies. He stated:

Prevention needs control attached to be realistic. (There is) no such thing as prevention in the context of current research and clinical practice. ... We've given up on prevention.

Dr. G representing the researcher idealism culture would characterize the perspective of Dr. B as conventional wisdom. The following passage from Dr. G demonstrates a clash by the researcher idealism culture with the conventional wisdom culture. The censure is directed to arena 4 (information support) and arena 5 (funding), considered conventional wisdom by the participant:

There is not a commonality with the funding sources [arena 5]. There, the desire is to keep the process of funding allve. so that both the funders and the recipients of the funding have a common objective of keeping each other operating. And the research resources like cancer registries [arena 4] really are not motivated to collaborate because they compete with other researchers for funding. Their objective is maintenance of records, not the conquest of disease.

In the next passage, Dr.G continues to express concern about the nature of conventional wisdom and explains why idealism gives way to "economic pragmatism." This provides insight into the genesis of the business culture which is driven by the economics he refers to here:

Research in the world of breast cancer starts out with idealism but that rapidly vaporizes and is replaced with an economic pragmatism. What the researcher learns is that there is a strong bias against innovation from funding sources. So that the secret to succeeding is to do something that is not ideas about the etiology of the disease, and essentially not rocking the boat. ... The vast bulk of the scientific community lives by other ideals -- to maintain the business of research, to keep the technicians 
BCP Culture/Leadership

employed, to keep the PI [principal investigator] employed.

The following passage from Dr.G adds to the nature of the business culture:

The [cancer information] registries are created out of idealism. Legislators and others believe that knowledge can cause an advance to prevention or cure, but that rapidly becomes institutionalized . . . and becomes a business of taking care of information.

The significance in this clash is the cultural issue that predisposes a certain belief system on the participant, and goes to the very heart of the research relating to the nature of current dominant cultural paradigms. This is not a clash between primary and secondary prevention strategies. It appears more to be a clash among researchers who have different cultures. One has accepted the conventional wisdom regarding prevention strategy, the other has not. The other maintains a fervent dedication to primary prevention as the ultimate weapon for eradication of the disease.

Participant researcher Mr. E working on his Ph.D. in Public Health had opinions on what he called "the conventional wisdom." He stated:

There is a belief by the conventional wisdom that it (cancer) can not be prevented. It's (the research effort) not directed at cause, they have given up on cause.

When asked what characterizes this conventional wisdom, he stated: "aversion to risk." He is of the opinion that the focus on treatment and drugs is due to an aversion to risk. In adopting the more accepted approach which is secondary prevention, there is lower risk and a perceived faster pay-back. Mr E stated:

I am isolated as a researcher. There is no sharing. Collaborators are reviewers mainly. There is little collaboration that share interest in cause. A small percentage of cases are gene oriented. Why all the time and effort? ... The culture has given up. They can't tackle the question. Cancer is too big a question for them. Therefore - they are adverse to risk. ... If a researcher proposed a study to prevent breast cancer, (he or she) would not be taken seriously. 
Mr. E contrasts risk aversion by conventional wisdom with advocacy groups early on (early 1990s):

They wanted answers now! They were willing to take risks. They had nothing to protect.

However, his comment as to the present status of advocacy was:

Advocacy now is adopting the same conventional wisdom type philosophy (that is) - prevention or cause determination is not feasible. Therefore the focus is on what short term result is achievable.

He is referring to the political activism sub-culture of activism that has taken a more political influence posture. compared to the more radical activists.

\section{Radical Activism vs Conventional Wisdom}

Stabiner (1997) describes a strategic meeting in 1993 between then Director of the National Cancer Institute (NCI), Sam Broder, and Fran Visco. President of the National Breast Cancer Coalition (NBCC). Fran states:

'We feel we have for the first time ever gotten a significant amount of money for breast cancer research.' she said. 'What are you going to do differently?'

Broder was a twenty-two-year veteran at the NCI, the head of the research team that in 1985 had discovered the therapeutic effects of the drug AZT in treating AIDS patients. He had been the NCI's director since 1988, and as a loyalist believed that the $\$ 210$ Million appropriation . . belonged within the (NCI). . . . He said nothing for a long moment, and then explained that the NCI was a huge battleship. He could not turn it on a dime. (p. 64)

One participant that maintained the radical activism stance is Ms. G. She participated in the focus group sharing her concerns about the future of the 
movement to transform breast cancer research. She commented, in a followup interview, on her fellow activist board members who "lacked moral resolve:"

They are in a fragmented survival mode. Money has become so much an issue. Also, lack of honest confrontation and communication of what the problems are so that they can be solved together in a unified manner, not in a combative mode.

Referring to the national activist groups, and the competition that developed among leaders of the various leading groups, she states: "It became a battle of who would be in charge."

These are examples of clashing -- within one activist board of directors in transition, and -- between different views at the national leadership level. It would appear that the sub-cultures of political influence and radicalism were battling for supremacy. However, there is another interpretation that is offered here. Observed is that political activism accepted the conventional wisdom as a means of sustaining the advocacy movement. Therefore, the clash is between radicalism and the status quo .- conventional wisdom.

\section{Business vs Clinical Medicine}

Participant Mr. T is an oncology social worker. He provides psycho-social services to patients and their families. He used the term "tertiary" in the context of prevention for the first time in the study. He considers what he does, as well as other oncology counseling services, to be tertlary prevention. This is prevention aimed at educating the individual and family so that they can best deal with the risk of disease, the diagnosis, and the treatment and healing. He pointed out that cancer is unique with the statement:

Fear of cancer is hard to overcome. It's hard to get mottvated about something that kills. 
It is his belief that the 1980 s ushered in a business culture to medical practice. Hospitals now compete for contracts in ways they never did before. Managed care and other cost containment methods are being imposed on medical professionals.

This new business approach combined with the rapid change in our society has created new pressures on all groups that must work together. He stated:

The emphasis is on care and treatment and drugs, not on research and prevention.

This is partially why many patients and practitioners are looking for new healing solutions. The "care and treatment and drugs" referred to by Mr. T is secondary prevention. His reference to "research and prevention" is primary prevention. Mr. $T$ believes the holistic movement has picked up momentum due to these issues.

\section{Business vs Outreacher/Patient Care}

An outreacher participant Ms $J$ who is a writer alluded to the potential clash between the business culture and the cancer community. She expressed concern over the issue of profit in a nonprofit environs. She asked:

What are the implications of allowing profit to be an incentive or orientation in health and human services? ... This is a major policy issue of our time.

It was her belief that business has moved into healthcare in a major way. She stated:

The real money in health is made by the insurance companies and the HMOs. Who is setting the policy, driving/steering the wheel in this direction? Its an avalanche. ... .

We've lost our common sense and replaced it with science. Does our complex world now necessitate science to solve problems in lieu of people, 
and common sense.

Her concern was that we, as a society, are replacing our intuitive abilities with scientific dependence. She highlighted a major policy clash regarding mammography:

We still don't know what causes the disease (cancer). The NCI and the ACS send different messages. One says mammography at 40 . The other says 50 . What do people do?

This outreacher participant is typical of those observed that are frustrated with science, yet at some level feel a dependence on it. Ms. J stated:

The center of the wheel is scientific research. Once we solve the human genome, we'll have answers. In the meantime, individuals need basic common sense. If you maintain diet and exercise. I think you go a long way. ... Its like a wheel with many spokes. You have the extreme activists, determined in their life time to find a cure. The medical community are baffled. The treatments have not changed in the last thirty years.

She sums up her thoughts on collaborations with:

There is a worship of individualism. We have a long way to go until people will work together.

Ms. $J$ represents the outreacher culture that wants to make a contribution, but does not have the "life or death" evangelism of the radical activist.

A patient care culture executive participant Mr. D expressed the need for collaboration:

There is a need for collaboration. Papers are presented, but no collaboration. There is little implementation. (They) go from meeting to meeting, not much happens as a result of it. There is no followup and effective communication, coordination. Diverse cultures do exist that have difficulty collaborating. . . . There is a struggle here due to egos and diverse agendas of different organizations. 
BCP Culture/Leadership

Mr. D's partial solution to collaboration was to innovate in those areas that his organization has control over, based on their mission that is patient care/support. An example is by "getting within" the communities they serve, they have been able to create a constituency of volunteers and workers that are committed to helping cancer patients.

\section{Collaborating Networks}

The premier example of collaboration was observed in a press conference hosted by the American Cancer Society (ACS) in November, 1996. The theme of the conference was the initiation of collaboration between and among the major organizations of cancer. Other examples were: Grassroots collaboration among activists: the ACS and communities collaborating in early detection interventions; and a San Diego clinic and local community collaboration.

\section{A Collaborative Initiative}

The only example of visible collaboration between major organizations observed during the study was the press conference in November 1996 hosted by the American Cancer Society. The purpose of the press conference was to present findings from a study conducted by the University of Alabama. The study indicated a decrease in overall cancer mortality over the last twenty years. mainly due to the decrease in smoking among men.

The significance of the conference was that it was the first event in which the three major cancer organizations collaborated in presenting information to the public. John Seffrin. Executive Vice President of the ACS, announced: "This is a first report card to the American people. We promise it will not be the last." Hellene Brown, advocate with UCLA Cancer Center, made a statement reference 
school education programs. It was an appeal to reach out for help to the community: "We are not getting the message across . . . If anyone has ideas on human behavior models, please share them with us."

Proposed by NCIs director Dr. Richard Klausner was the establishment of a national advisory board on policy that would provide consistent policies on major issues throughout the cancer community. He stated: " this board will create a neutral form to sit together on policy formation . . . we need national standards." The president of the American Cancer Society. Myles Cunningham. stated: "Everybody's got to be part of it to make it work." John Seffrin ended the conference with: "We have a challenge. We ask the american public to help us. If we work collaboratively, we can best serve the public."

\section{Grassroots Activism}

Observed were examples of collaboration that demonstrate the role of breast cancer activism as change agency. Participant $\mathrm{Mr}$. D stated:

Breast Cancer has changed the culture. People are getting together now, coming together on common ground, acknowledging their cancer and bonding to make change.

The paradigm has shifted since activism has taken hold. A breast cancer patient who, in 1988, was unwilling to participate in a research study, was posing in a magazine featuring breast cancer victims in 1995. Women. who believed they must remain quiet in the past and just take their chemotherapy. were beginning to ask: Why? Is there a more effective treatment for me, and my specific cancer?

The roots of this activism came from grassroots organizations throughout the nation that demonstrated a willingness to take action. They were no longer remaining silent. They were organizing and pitching in to the national cause.

Participant, Ms $\mathrm{J}$ provided a metaphor of collaborating networks with her 
description of concentric circles: "You drop a stone in the water creating concentric circles." She was referring to the impact that all can make collectively by their contributions. As an outreacher. she had experienced collaboration between cancer patients. museums, and sponsoring corporations. Together they created an exposition titled "healing legacies." It was an effective way of expressing feelings related to the disease, and thereby promoting healing.

Observed were examples of formal organizational initiatives designed to provide communication and coordination among breast cancer advocates. The national action plan for breast cancer is such an organization. Chaired by a breast cancer survivor/political activist, this group was formed to bring together the public and private sectors in a dialog. According to participant $\mathrm{Dr} \mathrm{B}, \mathrm{a}$ member of the action plan, the organization is more information sharing than leadership.

Another newly formed organizational initiative by the national breast cancer coalition is Project LEAD. LEAD has two meanings. The first being the obvious meaning that invokes leadership and action. The letters stand for Leadership, Education. Advocacy, and Development; subtitled: An innovative science program for breast cancer activists. The president of the national breast cancer coalition (NBCC). Fran Visco. states the vision of the organization on the brochure cover:

Money alone is not enough to end the breast cancer epidemic. We need to bring the perspective of the patient, the breast cancer activist, to the table where breast cancer research decisions are being made.

(Project LEAD brochure 1996/97. National Breast Cancer Coalition Fund)

Project LEAD, a formal organizational program. has been formed with the mission of creating educated advocates. It appears to be an example of fighting entrenched organizations with a new organizations. Although this appears to be an example of collaboration on the surface, and possibly it may be within the breast cancer organization, but it also is an example of the actlvism culture 
clashing with the existing dominant conventional wisdom. Conventional wisdom is what is referred to as "the table" where all the decisions are made.

\section{A Community Clinic}

An example of collaborating networks within the secondary prevention arena exhibiting the clinical medicine culture is a community clinic in an under-served population area of San Diego. Dr. $\mathrm{H}$, medical director of the clinic offered the following example:

We have a network of community educators that pretty much have a pipeline into the community through ESL classes, neighborhood agencies. that allow our educators to go into the community to do education. We have been doing it for so long that it does not involve that much . . . they know our staff and they know the kind of work we do.

As an example of an actor in the context of this research. Dr. Hill would be described as a executive-clinician. She is a physician faced with the need to be a manager as well. She provides care to her patients, but must also deal with resource issues, decision making, and community relationship building.

\section{"Getting Within" the Community}

Participant Mr. D, patient care executive, described how the American Cancer Society is quite effective in conducting early detection and education programs in ethically diverse communities. He called it "getting within" the community by hiring a staff person or a volunteer who is of the same ethnicity as the community. This may appear obvious, but it was not practiced historically. The person speaks the language, knows the culture, and therefore can relate effectively to members of the community at risk of disease. 


\section{Leadership Expression and Theory}

Emergent from the data was the theme of leadership. There appeared to be various perspectives or interpretations of what "type" of leadership was needed to improve the effectiveness of organizations and cancer prevention. Leadership was often connected with information sharing, collaboration, and cooperation. Leadership experienced and/or perceived and/or desired by participants is described in this section, and then linked where relevant to leadership theories.

Four examples of leadership experience is presented here: leadership as "tip of the arrow," leadership as "Project LEAD," leadership as "common sense," and leadership as "getting the product to market." The leadership experienced is developed within the frame of the participant's culture. The leadership experience is then related to leadership theory to enhance an understanding of the nature of leadership in each cultural framework.

\section{Leadership as "Tip of the Arrow"}

Leadership as "tip of the arrow" was expressed by Mr. D, executive-patient care participant who made the following statement:

There is a need for collaboration. Papers are presented. but no collaboration. There is little implementation. (They) go from meeting to meeting, not much happens as a result of it. There is no followup and effective communication, coordination. Diverse cultures do exist that have difficulty collaborating.

... There is a struggle here due to egos and diverse agendas of different organizations.

When asked what is missing, he responded with:

When you have a collaborative effort, someone has to take the lead. if not it flounders. . . Some of the collaborative efforts I have been involved in -they failed, because an organization did not take the lead. 
He then described his metaphor for leadership:

If you picture an arrow, on the tip there is the leader, and the other groups following. All are important to the process, but one up front who takes the lead. No question, there is somewhat of a void there now.

Greenleaf (1977) characterized leadership as: "going out ahead to show the way" (p. 96). He viewed great leaders as servants first. His theory of leadership extended to everyone in the organization, from the chief executive to the least skilled individual. In contrast to management and authority. leadership could be practiced by any one individual or any one organization in a community of organizations.

The cancer prevention community is a community (or metaorganization) of diverse organizations. Mr. D infers that one of these organizations within the community must take the lead in order for collaborative leadership to be effective. His "tip of the arrow" metaphor for leadership that "shows the way" is consistent with Greenleaf's (1977) theory of leadership.

\section{Leadership as "Project LEAD"}

Leadership as "Project LEAD" is expressed by the program developed by the National Breast Cancer Coalition (NBCC). Project LEAD (Leadership, Education. Advocacy. Development) is described by the NBCC literature as an innovative science program for breast cancer activists. Fran Visco, president of the NBCC. states in the Project LEAD brochure:

Money alone is not enough to end the breast cancer epidemic. We need to bring the perspective of the patient, the breast cancer activist, to the table where breast cancer research decisions are being made.

We want Project LEAD graduates to be everywhere that decisions about breast cancer are made.

Ms Visco has been effective at building coalitions that resulted in significant 
funding increases for breast cancer research. The leadership observed here is one of creating relationships of influence to be applied to the problem.

Burns (1978) and Rost (1992) theorized that relationships of influence were at the core of the political model of leadership. Burns writes that "extensive analysis suggests that political leadership emerges from a broader set of motivations" than just quest for power, for example. He includes in these motivations: "sensitivity to group attitudes, and acceptance of responsibility for meeting group desires" (Burns, 1978, p. 106). Leadership in this political context is comprehending and empathizing the needs of followers/constituents/collaborators, and acting to serve their needs.

Rost (1992) theorized that leadership is an influence relationship, not attributable to characteristics or traits of individuals. His definition is: Leadership is an influence relationship among leaders and followers who intend real changes that reflect their mutual purposes (p. 102).

Based on the four elements required for leadership to exist by Rost's definition. Project LEAD would be practicing leadership: The relationships are based on influence, leaders and followers/collaborators (patients, activists) are the people in the relationship, leaders and followers intend real changes (to prevent breast cancer), and the leaders and followers are engaged in mutual purposes. The political activism culture of Project LEAD is consistent with the theories relating to political leadership.

\section{Leadership as "Common Sense"}

Participant, Ms J provided a metaphor for leadership as "Common Sense" with her description of concentric circles: "You drop a stone in the water creating concentric circles." She was referring to the impact that all can make collectively by their contributions. As an outreacher, she had experienced collaboration between cancer patients, museums, and sponsoring corporations. Together they created an exposition titled "healing legacies." It was an effective 
way of expressing feelings related to the disease, and thereby promoting healing.

This outreacher participant is typical of those observed that are frustrated with science, yet at some level feel a dependence on it. Ms. J stated:

The center of the wheel is scientific research. Once we solve the human genome, we'll have answers. In the meantime, individuals need basic common sense.

... There is a worship of individualism. We have a long way to go until people will work together.

Leadership as "common sense," as Ms. J describes it, is interpreted as the community model of leadership. She, like many, hope to see the cancer community act as a community. The individualism she refers to is consistent with the competitiveness experienced in other cultures observed in this research.

Foster (1989) provides a community model for leadership. He described the search for community as an "ongoing and creative enterprise in which ... agents continually re-create social structure" (p. 45). He related leadership to community:

It is an enduring feature of human life to search for community; to attempt to establish patterns of living based on mutual need and affection, development and protection. ... The idea that leadership occurs within a community suggests that ultimately, leadership resides in the community itself. (p. $48-49$ )

The outreacher culture appears to fit the community model best. When Ms. J speaks of "common sense," her examples exemplify a sense of working together with commonality of purpose for the well being of all.

\section{Leadership as "Getting the Product to Market"}

Leadership as business management or "Getting the Product to Market" was expressed by a researcher/staff scientist, Dr. R, formerly with the National 
Cancer Institute, Participant Dr. R emphasized the competitiveness of researchers within the Institute as an impediment to collaboration.

Information sharing was deficient due to the desire of each researcher and each department unit to get funding, and the prestige that would come with being "the first." She compared the competition in cancer with that in AIDS research during the initial phases.

She expressed the nature of the competition with the following:

The word colleague was somewhat artificial .... The competition was just so incredibly fierce, in an area of science that was so exiting, that it took away from the science. Money is part of it, but prestige. I think, at this level of science was uppermost in their minds.

Dr. $R$ described the nature of collaboration experienced:

There was some collaboration, but in my division, it was not allot. . . I think it was dependent on how important it (the research) was. If it did not make a difference in who you were going to be in life, ok, (there was collaboration). where as with the level of science at NCI, its where it was at that point in history.

The degree of collaboration was dependent on the importance of the research. If the importance was significant, or if the project was meaningful and could result in important findings. then there was less collaboration or sharing.

Dr. $R$ expanded on the nature of sharing information:

You would present your research information at conferences, etc. supposedly to people of similar interest. but it was selected. There were certain things you would not release ... you didn't want someone else getting there before you.

When asked about a characterization of the organization culture she experienced. Dr. R provided the following:

It strikes me as being sort of a business setting. You've got a product, 
and you wanted to get the product out to market ... and then getting the credit for it. That's why they didn't want to share.

Dr. $R$ believes that the particular leadership or direction heading up the different departments determined the amount of collaboration. And this was based on the discretion of the leaders relating to the importance of the project and the need to derive credit. She shared that her love of science inspired her to join the NCI. However, she was unable to continue based on the organizational conditions that detracted from the pure science.

The discussion of culture and collaboration reminded Dr. R of a contrasting organizational example where positive collaboration is the norm. She described a friend's environment employed in research at Scripps Oceanography:

There is tremendous collaboration there. She (the friend) travels to visit colleagues to share and work together. ... Its prestige. Whether the person in charge is truly interested in the project, for the project, or for the project for where it will get him.

A conclusion from the interview is that the culture of the organizational unit is linked to the leadership experienced by members of the organization. This is consistent with Schein's (1987) theory that culture and leadership are intertwined. Competitiveness voids the possibilities for leadership to flourish. What is observed here is not leadership, based on the definitions offered in chapter-two: instead we have an example of management direction.

The critical issue in proclaiming the deficit in leadership is that change, at the transformational level, occurs through leadership. Organizational renewal, providing openness for new ideas to expand the vistas of an organization, would be considered transformational in nature. Management, in contrast to leadership, provides incremental change that results in optimum utilization of resources.

Therefore, an organization culture that does not encourage or experience 
leadership is one that may be stagnant, possibly even, dead. Bohannon (1995) informs us that unless a culture is changing, it is a dead culture. A dead culture is one that is static and unable to adapt to changing requirements and conditions in the environment it serves.

Mollner (1992) defined two fundamental worldviews: a material age, and a relationship age worldview. The material age worldview is based on the belief that the universe is composed of separate parts competing for self interest. The relationship worldview is based on the belief that the universe is composed of "connected parts, each of which cooperates with all other parts in the interest of the universe first and only secondly cooperates or competes in the interest of itself or any sub-group of parts" (p. 97). Clearly, the participant Dr. R had experienced an organization culture at the NCI that typifies the material age model or worldview.

The material age worldview is a model for business enterprise. Classically. a business is concerned with products, competition, and performance. The performance is measured in profit for private sector corporate enterprise. In government, performance is measured in "getting there first" and "getting the credit," as Dr. R stated. However, this old/classic worldview is being challenged.

A new worldview based on relationships (Mollner, 1992; Rost. 1992), and based on community values (Foster, 1989) is emerging that promises to replace the old models. This discussion of the two worldviews provides the framework for making the distinction between community and metaorganization.

A community of organizations would aspire to the leadership conceptions of Foster (1989), and have a worldview based on the "connected parts" philosophy described in Mollner's (1992) relationship age. A metaorganization. in contrast, would be based on Mollner's material age. Each organization within the metaorganization is competitive with the other, and does not share a common vision with the collective. The organizations within the 
BCP Culture/Leadership

metaorganization are more concerned with their individual survival than with the survival of the whole.

\section{Organization Culture and Survival}

The differences in prevention strategy philosophy are fundamental differences in belief system. Schein (1885) defines culture as the basic assumptions and beliefs that are shared by members of an organization. He states that these deeper level basic assumptions and beliefs operate unconsciously, and define "an organization's view of itself and its environment." These are learned responses to a group's need for survival in its external environment, as well as its issues of internal synthesis (p. 6).

It appears from the data that the root cause of the competition. or clashing, is culture differences that invoke a certain policy about prevention. With Schein's view of culture in mind, there could be more deeper issues that invoke the clashing - namely, culture survival. The cultures that are invested in secondary prevention may view the primary prevention community as a threat to their survival. The same may be valid in reverse. The clashing does not seem as severe with tertiary prevention. Possibly, this is due to the perceived reality by primary and secondary groups that tertiary is not threatening to their survival. Tertiary prevention may be viewed as complementary to other prevention strategies. Therefore, not competitive, and not a replacement for primary or secondary that would threaten their survival.

\section{Summary}

Emergent from the data are themes or action processes that are described by the researcher as "clashing cultures" and "collaborating networks." It appeared in numerous examples that the cultures identified were in a competitive/contrarian mode. This is contrasted to the condition of conflict. Conflict presumes the presence of open communication and a common vision/belief system. Conflict is defined in this study as disagreement 
surrounding a course of action for a problem.

Based on the assumption that individuals or groups in conflict share the same belief system, the condition of conflict was observed in the data relating to one major issue: mammography policy. Conflict pertaining to this issue was observed between the National Cancer Institute (NCI) and the American Cancer Society (ACS). In this case, both the NCI and the ACS share the belief that secondary prevention offers the greatest potential benefit for patients. The conflict therefore is over a publically recommended policy on how often women should have mammography interventions.

Clashing in contrast to conflict, in the context of this study, would be a case where the NCI supported primary prevention, and the ACS supported secondary prevention. The clashing would be due to differences in beliefs about prevention that go deeper than a policy in which the basic assumptions between groups (or cultures) are aligned. It was observed in the study that secondary prevention is the accepted dominant strategy by both the NCI and the ACS. Therefore, they may be in conflict relating to the mammography public policy, but they share a common belief that mammography -- as a secondary prevention strategy -- is the right approach.

Three examples of clashing are noted here that appear to be the most significant observed. The criteria for significance is based on the researcher's assessment of the impact that each has had on the status of prevention policy and potential change.

The first is one based on belief system differences observed between two researchers that represent different prevention strategies. Dr. G and Dr. B both appeared to be competent, well meaning participants that held strong beliefs on how cancer research should be focused. Dr. G expressed a strong belief that the cause of cancer could be discovered through primary prevention. This is described in this study as research idealism culture. Dr. B expressed a strong belief that primary prevention research was no longer feasible. His attention 
was on secondary prevention as it is defined in this study. This is described as conventional wisdom culture in this study because it is the accepted policy by the major institutional organizations.

The second is the major "collision" that took place when BC advocacy first emerged in the early 1990s. The conventional wisdom institutions did not accept the radical change proposed by the movement. This was apparent from the many hearings that took place to debate policy relating to breast cancer. The clash was based on the belief by conventional wisdom that research funding was being spent appropriately, defending its policy on funding basic research and secondary prevention related programs. The breast cancer activists questioned these status-quo beliefs, offering new initiatives focused on primary prevention and eradication of the disease.

The third example of clashing was observed relating to vision and direction within breast cancer advocacy organizations as the movement matured. One activist participant Ms S. shared her anger and frustration that resulted from her Board of Directors not confronting the serious issues dividing its members. She stated:

There is a lack of moral resolve on the part of Board members. . . . They are in a fragmented survival mode.

It appears that a split occurred, at some point in the process, between advocates desiring to accept the conventional wisdom- and those that did not. The advocates who accepted the conventional wisdom through a policy of working within the system -- are named in this study: political activists. Project Lead. created by political activists, is an example of a program that attempts to create power and influence through a political process.

Political activists have adopted the long term results and benefits strategy. Therefore, this means they have accepted the direction of the conventional wisdom, which also means that have accepting secondary prevention as a 
strategy.

The radical activists clash with these beliefs and policies by the political activists. They believe that new models and methods are critical to make swift change to save lives -- now. They have reached out to alternative medicine and the arts to find collaborators and innovative ideas for change.

Three examples of potential networks of collaboration are: (a) the November 1997 press conference announcing the collaborative goals by the three major cancer organizations, (b) collaboration between a community clinic and community leaders to educate the public on early detection, and (c) the initial grassroots phase of the breast cancer advocacy movement.

Other themes that emerged from the data are the need for more information sharing, cooperation, collaboration and leadership. Frequently observed were differences in philosophy/belief system, or frustration with how things are done, or where there is no open communication. These are interpreted in this research as competing ideas, or clashing, because the apparent means or concern for collaborating through conflict was not apparent. 
BCP Culture/Leadership

\section{Chapter VI: Transformative Change Theory}

\section{Introduction}

Chapter IV described nine organization cultures observed in the study. and the connections between the cultures. The connections were based largely on the prevention policies shared by the particular cultures. For example, observed was the connection between researcher idealism and radical activism. This connection was based on the shared belief that primary prevention is key to cancer eradication, and therefore, should be given more funding. Chapter $\mathrm{V}$ illustrated the nature of dis-connections between cultures characterizing them as clashing phenomenon.

This chapter develops theory relating to a major dis-connection or "clash" between cultures observed. Specifically, the interaction of the dominant culture observed (conventional wisdom) and the cultures contained in the breast cancer advocacy movement. Suggested from the research was that this interaction involved complex organizational processes, a time dimension, and stages that resulted in a significant turning point for cancer prevention policy. This particular clashing phenomenon is the focus of the theory development in this chapter because it relates directly to the study activity context of the research. i.e., the intersection of cancer prevention policy, organization culture, and breast cancer advocacy.

Theorized is that the turning point driven by the clashing of conventional wisdom and advocacy resulted in a transformation in the study activity context. A distinction is made here between transformative change and incremental change. Incremental change occurs within the boundaries defined by conventional wisdom. Transformative change is change that generates a turning point, moving outside the boundaries of conventional wisdom. This type of change can renew/redefine the paradigms and metaphors that set/underlie the 
boundaries of a dominant culture. For example, transformative change could lead to the reformulation of cancer prevention policy.

The theory developed in this study is that breast cancer advocacy influenced transformative change in cancer prevention policy. This change resulted in a shift from a policy of secondary prevention exclusively to a policy of renewed interest in primary prevention, and increased levels of funding for breast cancer research.

The chapter first briefly describes the advocacy movement of the early 1990s that set the scene for the interaction and change. Then, the clash between the cultures is explicated, followed by a description of the outcomes, and concluding with a summary of the theory development key elements.

\section{The Advocacy Movement}

Breast cancer (BC) advocacy had existed in some form prior to 1990 . However, a series of events and factors (outside the scope of this research) led early in the 1990s to a formidable coalition of concern about breast cancer incidence and mortality, redefining advocacy into a serious and powerful force for change. The concern became manifest in the formation of many grassroots organizations such as Y-ME, ONE in NINE, the Breast Cancer Action Group. and the Women's Cancer Task Force. Ultimately, this led to the formation of the National Breast Cancer Coalition (NBCC) which became a highly visible and respected venue for political action. The patient awakening, public opinion momentum, and eventual change results qualify the phenomenon as a "movement;" possibly with the passing of time, it will be considered a major social movement depending on what unfolds in the next phase of the movement.

One of the factors in the awakening was the insistence by $\mathrm{BC}$ advocates to attain accurate information on the statistics of breast cancer. This data became the basis for the battleground. For the first time, women were informed of the disconcerting reality of the disease with facts such as: breast cancer incidence 
rates have steadily increased since $1973, \mathrm{BC}$ is the leading cause of death for women aged $35-54,75 \%$ of new cases are diagnosed in women with no family history of breast cancer (Cancer Facts and Figures 1996, National Cancer Institute).

An item that inspired political action was that in 1990, the dollar value of medical care for the nation's breast cancer patients was estimated at over $\mathbf{\$ 6}$ billion -- yet funding for breast cancer research equaled only $6.7 \%$ of that cost (Cancer Facts and Figures 1996, National Cancer Institute). Becoming informed opened the eyes of many for the first time, and this led to action. In 1991, funding for breast cancer was $\$ 92.7$ million; by 1993, funding had reached \$196.6 million.

The $\mathrm{BC}$ advocacy movement was about creating change. The issue addressed in this research is the influence and interaction of the movement with the existing culture establishment that was the recipient of the change request: the conventional wisdom.

\section{The Interaction and Outcomes from Clashing Cultures}

The momentum of BC advocacy, with a resolute agenda for change, clashed with the conventional wisdom ( $\mathrm{CW}$ ) which represented the status quo. The interaction of the transformative change engine of advocacy clashing with a dominant, entrenched culture resulted in two significant outcomes. The first was a positive transformation that resulted in increased funding levels for breast cancer research. and renewed interest in primary prevention research. However, the resistance sustained by the conventional wisdom culture resulted in a second outcome that involved a fragmenting of BC advocacy. Advocacy constituent organizations had to choose between short term pressure on the establishment for immediate change, or alignment with $\mathrm{CW}$ for long term change. This split in strategy by $\mathrm{BC}$ advocates generated the outcomes portrayed in figure VI- 1 . 
New cultures were created from the clashing described, they are: radical activism, political activism, and outreacher. Figure VI-1 portrays the differentiated outcomes resulting from the breast cancer advocacy movement. and the resultant cultural alignments. Prior to the movement, the dominant support from the conventional wisdom culture was to secondary prevention. The change that resulted from the onset of the movement was the creation of three new cultures that supported different prevention strategies. Radical activism supported primary and tertiary prevention. Political activism supported secondary prevention. Outreacher culture supported all three prevention strategies. The alignments with other cultures were not always explicit, and are inductive in nature. Radical activism appeared to be aligned with holistic and researcher idealism cultures. Political activism appeared to be aligned with conventional wisdom and clinical medicine cultures. Outreacher appeared to be aligned with patient care and holistic cultures.

As activism in the early advocacy stages matured, it was shaped by many forces. These forces are discussed here in the context of a process that unfolded between 1990 and 1995. Within this time-frame, BC advocacy changed from many loosely formed grassroots activist organizations to fewer formal organizations. The theory offered in this study, grounded by interviews with a sample of participants and observations of the researcher, is that a process took place during the time-frame defined -- that generated changes in the organizational culture (or metaorganizational culture) of cancer prevention.

Out of the context of cancer prevention policy, and influenced by the "combat" of advocacy, the action processes that resulted were a clashing of cultures. The consequences from the action process are: differentlation of cultures, assimilation of cultures, survival of cultures, and potential extinction of cultures. 


\section{Summary of Theory Elements}

The transformative changes in the culture and policy of cancer prevention. influenced by breast cancer advocacy, are summarized as follows:

1. The dominant and exclusive policy of cancer prevention was no longer secondary prevention for breast cancer as a result of breast cancer advocacy influence. Primary prevention emerged during the process as a renewed candidate for higher funding.

2. During the initial stages of the process, $B C$ activists were united in changing the "old models" that dominated all policy relating to breast cancer (which would impact all cancers) as a chronic disease.

3. As the process of transformation evolved, a differentiation began within the ranks of the $\mathrm{BC}$ advocacy movement as a whole. Belief systems that were unified and internally integrated within the movement started to break down.

4. The conventional wisdom during this process remained steadfast in their beliefs and assumptions regarding secondary prevention.

5. Three differentiated outcomes observed resulted from a collision with the dominant conventional wisdom. These outcomes are viewed as distinct cultures in this study based on Schein's (1987) definition of culture in organizations.

6. Three cultures emerged from the process. as observed in this study: radical activism aligned with primary and tertiary prevention, political activism aligned with secondary prevention, and outreacher aligned with all three strategies.

\section{Summary}

Theorized is that the influence of BC advocacy on the conventional wisdom of cancer prevention policy, in the early 1990s, was to effect policy on the prevention strategies of primary and secondary primarily. Furthermore, the impact of advocacy "colliding" with conventional wisdom resulted in three differentiated cultures: radical activism, political activism, and outreacher. Each 
of the three cultures formed special alignments with the prevention strategies. As a result of the new alignments, connections were made with other existing cultures.

The new cultures that were spawned from the power of the movement have distinct beliefs and values. Each has its cultural alignments within the community. Each supports one or more prevention strategies. The advocacy movement transformed the arenas of prevention from a total focus on secondary prevention to a renewed focus on primary and tertiary. The cultures most responsible for the change are radical activism. and outreacher. Political activism maintains support for secondary prevention. 
BCP Culture/Leadership

\section{Chapter VII: Researcher's Perspective}

\section{My Role as Cancer Registry Manager and Activist}

My involvement began in 1984 as a result of a diagnosis of cancer in my family. However, my motivation transcended concern for my family's health. I was driven by a desire to share a vision for cancer research. a vision based on the idea that improved sharing of information could improve cancer outcomes.

At the time. I was project manager of a worldwide information system that utilized data bases in extraordinary ways, to solve age old problems in antisubmarine warfare. The Rapid Feedback System, as it was called, was a big success. It shifted paradigms on what made torpedoes ineffective at catching submarines. I had first hand knowledge of what systems and teams could do when designed right. It was this knowledge that I could contribute to the solution of a much more serious problem. Saving lives seemed a better use of my expertise than saving torpedoes, and I believed that the cancer community would embrace this knowledge.

After serving in volunteer roles initially. I eventually was asked to develop the proposal for the San Diego/Imperial County Organization for Cancer Control (SANDIOCC), and became its first program manager in 1987. In retrospect, they (the cancer establishment/conventional wisdom) really didn't know how to deal with me. They needed my state-of-the-art knowledge to design cancer registries, but I was an outsider with political connections.

A cancer registry manager was usually a career cancer type, not an engineer with a master's in management, and sophisticated experience in the outside world. I also came with a real success story. I had designed and managed a model for data base management that could be replicated for cancer registries. In my naivete. I did not prepare myself for the battle (or the clashing of cultures) I would encounter. 
This research has provided me with a framework to understand more of what was taking place during those years of my involvement. I had an intuitive and experiential sense of what happened, but now it has shape and definition. Some of my beliefs have been validated, others have changed. I concur personally with the data in this study. I discern now how the cultures were operating, and how conventional wisdom was the prevailing force that dictated policy thinking, and how colleagues viewed each other.

My understanding of leadership now integrates both theory and practice. Visions remain only visions, without effective leadership. Leadership means building relationships that support a vision. Leadership means sustaining the relationships and renewing the vision with time. Leadership means being patient, for visions do not happen in the near term.

If I had remained in my formal role, I would likely have embraced conventional wisdom to survive in the culture that provided financial support and prestige. I was moving gradually to a philosophy of incremental change. I would do my best to make change, but within the accepted constraints of the system -- within the boundaries of the dominant culture of conventional wisdom. Two leaders of the breast cancer advocacy movement were faced with this choice. One opted for radical activism resulting in rejection/extinction: the other for political activism resulting in acceptance/survival. Both served an invaluable service to breast cancer patients -- past, present, and future. Both created leadership -- but, based on different paradigms, and with different outcomes.

Stabiner (1997) describes various perspectives of cancer officials in her recent book To Dance With the Devll: The New War on Breast Cancer. Examples are: Donna Shalala (Health and Human Services Secretary) who believes in management by forced cooperation. and Harold Varmus (Director, National Institutes of Health) who believes in what he called "creative chaos." Stabiner tells us that Dr. Varmus did not believe in coordination, or in an "orchestrated" 
research plan of action. He believed in competition and "survival of the fittest" as a paradigm for research.

I respond to this with concern and a request that Dr. Varmus review the history of disease prevention and major program achievements. If NASA worked with the Varmus paradigm, entrenched in Mollner's "material age" of competing parts, we would still be hoping to reach the moon. I respectfully submit that Dr. Varmus, and others of the conventional wisdom, revisit their well intentioned motivations. It is my belief that conventional wisdom is driven by a quest for organizational culture survival. "Survival of the fittest" worked well for primitive beings, but it does not work well in a civilized society. "Survival of the fittest" is really about "survival" -- survival of one culture over competing cultures.

Solving the cancer puzzle will require more that individual achievement and ego gratification. It will require a dedication to the collective whole. Those afflicted by cancer, and those at risk of affliction (all of us) deserve more from our public officials. In a time when taxpayers are angry with those on welfare, rebuked for exploiting society; it is remarkable that we accept the non performance of cancer research. The impact of cancer on our society, in terms of cost and human suffering, is much greater than welfare.

\section{Did We Take the Wrong Turn?}

One-hundred years ago, another chronic disease plagued society: pellagra. Pellagra was a disease that was viewed very much as cancer is today. There was no cure. Clinics were established to treat those afflicted with the dreaded disease that ravaged the body, and in some cases, caused insanity in its victims.

We never learned the fundamental biology of pellagra. We never expended billions on research. We never created institutions and industries to treat the disease. But, pellagra no longer exists. Pellagra was solved as other chronic diseases had been solved like cholera, and small pox. Joseph Goldberger, a public health epidemiologist, was assigned the task. Within five years, he had 
determined that pellagra was caused by a niacin deficiency. Industrial society had designed machinery to process wheat. In this industrial process, niacin was removed from the wheat fiber. Therefore, replacement of niacin into bread production was the intervention and solution that eradicated the disease.

We must ponder this, and go deeper, to understand the significance of pellagra primary prevention in our present context. Provoking questions could have been raised at the time to stimulate scientific research about pellagra. What is the nature of this disease that afflicts some, and not others? What is the difference in their cell biologies? How does pellagra function and grow in the body?

However, the intellectual capital of the time, and industrial entrepreneurship was not interested in these issues of the pellagra disease. They were focused on other projects relating to science and engineering in an emerging industrial society. Therefore, we never came to learn more about the disease of pellagra. We know much more about cancer, possibly much more than we need to know, if eradication is the goal. Is it possibly that at some point in time, we took the wrong turn on the road to solving cancer. Are we using the right approach? Or viewed another way: Are we working within the right paradigm. the right metaphors?

\section{Paradigms, Metaphors, and Meanings}

Paradigms and metaphors assist in defining cultural/conceptual frameworks within which problems may be understood and ultimately solved. A paradigm is the ideal model, example, standard that all is measured against to discern appropriateness. Foster (1986) offers:

The paradigm ... defines what are researchable questions and acceptable answers; it provides the boundarles for investigation into the area of concern. A paradigm also governs the dominant metaphors in a fleld of study. 
Metaphors are images, symbols, allegorles that help us to understand that which we are trying to comprehend. Schatzman (1973) suggests the use of metaphor to assist in defining the key linkage and meaning in data collected.

Foster (1986) develops four paradigms that may be operating in a field of research or cultural setting: functional. interpretive, radical humanism, and radical structuralism. I will discuss the three that best apply to the data in this research: functional, interpretive, and radical humanism.

The functional paradigm is based on the assumption that the social world is objective, and concrete. The scientist can stand outside of it and measure it. All has a purpose in this paradigm, all serve some ultimate interest. I consider the functional paradigm to be that of conventional wisdom (CW) and "good science." There is a mind-set in the cancer metaorganization driven by the $\mathrm{CW} /$ functionalist paradigm that "we all have our jobs to do, and we must do them well; don't question. don't rock the boat, be cautious of outsiders, be loyal to each other; the patient is our customer, cancer is not a good thing, but -- we must all die of something."

The interpretive paradigm is based on the assumption that the organization is a social construct, not objective reality. Individuals are the reality, and are capable of constructing and interpreting meaning. This is a paradigm of questioning the accepted reality. I believe that radical activism was driven by this paradigm. Unwilling to accept the objective, accepted standards set by $\mathrm{CW}$. they rebelled to transform organizations based on a new paradigm of changing the "old models."

Radical activism evolved into political activism for some in the advocacy movement after the clashing with conventional wisdom. The movement fragmented into different cultural outcomes. The fragmentation was due to the clash with $\mathrm{CW}$, but may have been fueled by a paradigm difference as well. I believe the political activists embrace a different paradigm and assumptions from the radical activists. The radical humanism paradigm more closely fits the 
evolved assumptions of political activists. This paradigm shares much in common with the interpretive. However, in this paradigm. individuals certainly create their own worlds, but those worlds assume a historical structure in which arenas of power, and thus domination, become a major factor. In other words, the political activist believes you have to work within the power structure to get results.

Individuals and groups form conceptual frameworks, derived from basic assumptions and beliefs, in order to operate and relate to each other in the process of problem definition/solution. Groups, that consciously or unconsciously agree on basic assumptions and beliefs, form cohesive cultures. Cohesive may be a redundant adjective in describing culture because a culture by definition is a cohesive "body."

\section{Key Linkage: The Expanding Collage}

During the data analysis, the question that surfaced was: What does this data really represent? Strauss (1987) asks: What is really going on here? Emergent from this research study is that the data are unique perspectives from differing functional arenas and cultural orientations. This was followed by: What is the meaning of these data? What is the key linkage? What metaphor would facilitate an understanding of how the data forms a meaningful whole?

The over-arching theme or metaphor for this research is an expanding collage. Figure VI-1 pictures the different perspectives from the data that make up a collage. A collage is defined by Webster's as "an assembly of diverse fragments." The imagery of the collage fits the data because the unique perspectives are diverse fragments that once assembled form the picture of a breast cancer prevention (BCP) metaorganization of different organizations and individuals that are informally linked.

The concept of metaorganization is more appropriate than community based on the chosen metaphor of a collage. The concept of community conjures a 
sense of wholeness that was not found in the data. The metaphor for community would more likely be an orchestra. where the whole is more than the sum of its parts. This is not the case with the data from this study. The data are diverse culturally based perspective fragments. Together they are not more than the sum. There is something missing that would create a wholeness. Therefore the collage is chosen to comprehend the nature of the data in its totality.

Another interpretation is that the collage represents diverse fragments that collectively don't tell a story because they are not unified. A distinction can be made between the collage as metaphor and a more desirable condition: a unified vision. The diverse fragments or elements are the different culturally based perspectives. The collage then symbolizes the random assembly of the diverse cultures/perspectives that collectively is the breast cancer prevention metaorganization.

What is the meaning of the expanding collage metaphor in the context of this research? What are the implications of the expanding collage as metaphor? How does the war on cancer and cancer prevention as a collage of perspectives compare/relate to other social and governmental projects or phenomenon?

The Apollo project of the 1960s and the Silicon Valley phenomenon provide contrasting metaphors that give insight as to the appropriateness of the cancer prevention collage metaphor Varlous metaphors fit the Apollo project: a laser beam, or target end point consisting of disciplines focused on one unifying vision: an orchestra based on the masterful coordination of diverse elements; and the torpedo metaphor based on the honing in on the target which was the moon.

The silicon valley phenomenon was a technological explosion that can be characterized as an expansive collage of eclectic ideas, competing visions, and personalities. They were, and are, many organizations -- a metaorganization possibly, that can be characterized as an explosion of products in an ever expanding industry. This industry was created and continues to expand based on innovation, competition, and demand for new products. 
The war on cancer is comparable to the sllicon valley phenomenon. Both exhibit characteristics of competition, innovation. and "getting the product to market." Both are driven by proflt and prestige (ego). However, the difference is the nature of the dominating cultures. Conventional wisdom, in the context of cancer, guides the expansive collage of perspectives/approaches with a risk adverse mind-set. The silicon valley collective culture is driven by a conventional wisdom that all is possible. innovation is king, risk is not only good, but necessary for success. We must ask: Is this the appropriate metaphor for cancer prevention, and does conventional wisdom, as the dominant culture, serve the goals of preventing cancer.

\section{Leadership, Culture, and Change}

Schein (1985) tells us that a major purpose of leadership is to change cultures that no longer serve the whole. His deflnition of culture again was:

Culture is a pattern of basic assumptions - invented. discovered, or developed by a given group as it learns to cope with its problems of external adaptation and internal integration - that has worked well enough to be considered valid and. therefore, to be taught to new members as the correct way to perceive, think, and feel in relation to those problems (p. 9).

Leadership and culture are intertwined. They really cannot be separated as you can not separate the cake from its ingredients and recipe. Culture includes leadership, and leadership includes culture. Culture is the end result -- the manifested product from leadership. When I falled to do leadership during my cancer registry reign, the result was -- no culture. The result of all the presentations and visions did not produce a definable culture that included all of the organizations participating.

The culture that emerged and survived is that of a small group of "believers" -- radical activists and research idealists. We have a culture, we have 
BCP Culture/Leadership

a vision and a soul, but we have not, as yet. expanded our vision to build constituents that would represent a renewed quest for preventing cancer. This would take a renewed leadership, and changing cultures -- ours, and theirs.

Leadership is hard. Leadership means turning the organizational "ship's wheel" in a storm to avoid collision. or discerning that the collision should take place to break the culture. Organizations must create, or break culture based on issues of community wholeness: What are the needs of a community, and how are the needs best served?

Toffler's (1980) Third Wave theory that institutions are not serving us any longer, and Singer \& Grismaijer's (1995) statement that "we can't trust our culture" are aligned. Because the culture dominated by material age paradigms -conventional wisdom -- is doing all it can, in desperation, to survive in a changing world. A new model based on relationships, collaboration, and community offers promise, as we enter the twenty-first century, to overcome the "material age" entrenched conventional wisdom.

Foster (1989) suggests that it is an enduring feature and need of human life to search for community, and that leadership lies in the struggles of a community to find meaning for itself. The culture battle of cancer is a microcosm of the battle pervading societies. It is a battle for the hearts and minds of the collective human consciousness. Do we as a people return to the "material age" of competition, war, and death -- or do we evolve the human species to higher forms of community -- in which life is valued.

The cancer metaorganization is dominated by a culture that lacks leadership. The culture of conventional wisdom based on control, closed systems. and survival is driven by a form of "material age" management direction. Leadership does not reside in this milieu. Leadership implies change, openness. mutuality, and the sharing of ideas for the benefit of the whole.

There is hope, however, in cultures such as patient care and holistic, that are open to change and have embraced the breast cancer advocacy movement. 
There is hope as well in the human potential of those individuals trapped in conventional wisdom and classic clinical medicine mind-sets -- to break away from the existing paradigms, and join others in creating new communities that combine the best of the old with new visions. 
BCP Culture/Leadership

\section{Chapter VII: Summary, Conclusions, Implications, Recommendations}

\section{Summary}

Chapter IV described nine organization cultures observed in the study, and the connections between the cultures. The connections were based on the prevention policy shared by the particular culture. For example, observed was the connection between researcher idealism and radical activism. This connection was based on the shared belief that primary prevention is key to cancer eradication, and therefore, should be given more funding.

Chapter $\mathrm{V}$ illustrated the nature of dis-connections between cultures characterizing them as clashing phenomenon; and provided examples of collaboration as well as clashing between cultures. Expressions of leadership as experienced by participants were explicated.

Chapter VI developed theory relating to the dis-connections between cultures. Specifically, the interaction of the dominant culture observed (conventional wisdom) and the cultures contained in the breast cancer advocacy movement. Suggested from the research was that this interaction involved complex organizational processes, a time dimension, and stages that resulted in a significant turning point for cancer prevention. The turning point included a refocus on primary prevention and eradication of cancer, and away from secondary prevention as the exclusive focus of funding. The "collision" between conventional wisdom and advocacy, over the prevention policy, resulted in a fragmentation of advocacy into three diverse cultures: radical activism. political activism, and outreacher. Radical activism connected to researcher idealism remained steadfast in their beliefs regarding primary prevention policy. Political activism adopted a more aligned posture with conventional wisdom, supporting secondary prevention policy. The outreacher culture remained more neutral in support of policy, but was differentiated from the other two cultures by not 
adopting either posture, and remaining in a support role to cancer patients.

\section{Conclusions}

1. The breast cancer prevention community is not a "community" as it is defined in this study. Rather, it is an assembly of diverse organizations and individuals that are involved formally, or informally, in various aspects/arenas of prevention. The term "metaorganization" more accurately characterizes the nature of the organizational milieu. A community, as defined in the study, has common shared visions, beliefs, and a cohesiveness. The metaorganization of breast cancer prevention consists of different visions, beliefs, and is not cohesive or aligned. The lack of alignment is due to the existence of different cultures that exhibit differing visions and beliefs regarding prevention strategy.

2. The dominant culture conventional wisdom dictates the policy direction of breast cancer prevention. That policy at present is based on a major commitment to secondary prevention. Conventional wisdom is supported in this policy by other cultures: clinical medicine, business, pattent care, and to a lesser degree -- political activism and outreacher. It is clear from the positioning of these cultures that the future of cancer prevention lies in a prevention strategy that prevents mortality -- not morbidity (incidence). Prevention research, aimed at eradication of the disease, is supported by research idealism and the new breast cancer activism cultures. It does not appear likely that these cultures have the power to impact the long term direction of policy.

3. The breast cancer advocacy movement made a short term impact on cancer policy that included significant increases in funding for breast cancer research. The advocacy movement lost momentum, however, due partially to culture differences that resulted from the clashing with conventional wisdom. Activism was split between political and radical activism. lessening the impact of the movement to change prevention strategy from secondary to primary.

4. Various expressions of leadership were observed, not observed was a 
unifying leadership focused on creating consensus, and integrating the different cultures. There is a need for collaborative leadership in the cancer metaorganization studied.

\section{Implications}

The implication of a dominant policy of secondary prevention is the continued sanction of cancer and cancer's organizational support systems in society. Cancer will continue to be a major health risk. and the organizations supported by cancer will continue to grow. Therefore, we as a society, can expect to "live with" or "die from" cancer in our life-time. The "urgency to find answers" by breast cancer advocates has been impeded by the collision with conventional wisdom. An implication is that the advocacy movement has been neutralized, at least for now. Hopefully, this is a short term condition that will be followed by renewed leadership.

The implications from the research. in the context of organization culture. is that culture plays a major role in the development, management, and leadership of organizations. The inter-relationship of the cultures, in an organizational setting, dictate the policy formulation and long term direction of the organization and/or the group of organizations that have a common link. The culture is defined by the basic assumptions and beliefs of the collective, that includes the need to integrate internally and externally for survival of the organization.

The implications for future research relating to the breast cancer advocacy movement and organization culture are based on certain new questions posed: What issues -- organizational, cultural. political. social, psychological, contributed to the three differentiated advocacy cultures that resulted from the clash with conventional wisdom? In other words, what caused advocacy to split into three different factions? What are the future plans of advocacy to address these issues? Who are the new players in advocacy? Is there renewed leadership 
BCP Culture/Leadership

expression? What contributes to the dominant nature of conventional wisdom?

\section{Recommendations}

In 1962. President Kennedy gave a speech that launched the APOLLO program and the creation of NASA. He said in that speech:

"We choose to go to the moon, and in the decade, not because it is easy -but because it is hard."

This challenge propelled and sustained the NASA community to achieve the vision of reaching the moon before the end of the decade. With cancer posing a chronic and epidemic threat to our society, we need leadership at the highest levels to summon the same type of challenge. The leadership must be aware of the cultures that presently exist, and be prepared to change them -- and possibly break the dominant culture -- to create the unified vision necessary for success in a complex mission.

Recommended is the establishment of a NASA type leadership organization, outside the National Institutes of Health. with the authority and funding power to redirect the diverse organizations presently involved in cancer prevention. The National Cancer Institute's culture and research policy of secondary prevention, does not inspire the leadership that will ultimately result in the prevention of cancer. All existing organizations would provide advisory roles to the lead organization -- responsible and accountable for success. This will provide the organizational "body" with a "head" and a unified vision that it presently does not have -- capable and willing to create a community focused on the eradication of cancer. Recommended is a master plan developed and signedoff by all stakeholders as the first task for the leadership entity.

As a key component of the master plan. recommended is an educational and cultural awareness program, aimed at core workers in cancer organizations -- to initiate a transformation in consciousness. The malignant tumor, no longer in alignment, and communicating, with the body system -- is alienated and 
insecure. It is no longer programmed, as are healthy cells, to contribute to the well being of the total body community. "Survival" is provoking its aggressive movement. Existing organizations that support cancer are threatened by the possibility of elimination -- if cancer were to be eradicated. Therefore, they are not in alignment with the well being of society. This program would be designed to address the issues of those who have dedicated their careers to cancer work.

Recommended is renewed collaborative leadership in breast cancer advocacy to bring together the three cultures. This would renew the issue of real intended change in conventional wisdom, and support the transformation necessary to create real progress in cancer prevention. 
BCP Culture/Leadership

\section{REFERENCES}

Baker, E. L. (1980, July). Managing organization culture. Management Review, pp. 8-13.

Bellah, R. N., Madsen, R., Sullivan, W. M., Swidler, A., \& Tipton, S. M. (1985). Habits of the heart. New York: Harper \& Row.

Bergquist, W. (1993). The postmodern organization: mastering the art of irreversible change. Jossey -Bass: San Francisco.

Blumer, A. (1969). Symbolic interactionism; perspective and method. Englewood Cliffs N.J.: Prentice Hall.

Bohannan, P. (1995). How culture works. New York: Simon \& Schuster.

Bowers, B. J. (1988). Grounded theory. In B. Sarter (Ed.), Paths to knowledge: Innovative research methods for nursing (pp.33-59) (NLN Publication No. 15-2233). New York: National League for Nursing.

Boyle, R. J. (1985. Spring). Why wrestle with jellyfish?: Lessons in managing organizational change. National Productivity Review, pp. 180-183.

Bryson J. M., Crosby, B.C. (1992). Leadership for the common good. San Francisco: Jossey-Bass Publishers.

Burns, J. M. (1978). Leadership. N.Y.: Harper and Row.

Chenitz, W.C., Swanson.J.M. (1986). Qualitative research using grounded theory. In W.C. Chentitz \& J. M. Swanson (Eds.), From practice to grounded theory: Qualitative research in nursing (pp. 39-47). Menlo Park, CA: Addison Wesley.

Cuomo, M. (1995). Reason to believe. N.Y.: Simon \& Schuster.

Deal, T. E., Kennedy, A. A. (1982). Corporate culture. Reading, Massachusetts: Addison-Wesley.

Dollard, J. (1939). Culture, Society, Impulse, and Socialization. American Journal of Sociology, 45, 50-62.

Dossey, L. (1993). Healing words. New York. N.Y.: Harper Collins. 
Dyer, W. G. (1984). Strategles for managing change. Reading, Massachusetts: Addison-Wesley.

Fagerhaugh, S.Y. (1986). Analyzing data for basic social processes. In W.C. Chentitz \& J. M. Swanson (Eds.). From practice to grounded theory: Qualitative research in nursing (pp. 133-145). Menlo Park. CA: Addison-Wesley.

Fishman, W. H. (1995). LaJolla Cancer Research Foundation: The miracle on Torrey Pines Mesa. LaJolla:LaJolla Cancer Research Foundation.

Foster. W. F. (1989). Toward a critical practice of leadership. In J. Smyth (Ed.). Critical perspectives on educational leadership (pp. 39-62). London: Falmer.

Gamst. F. C. (1995). Meanings of work: considerations for the twenty-first century. Albany, N.Y.: State University of New York Press.

Gouillart, F. J., Kelly, J. N. (1995). Transforming the Organization. New York: McGraw Hill.

Harman. W. H. (1988). Global mind change. New York: Warner Books.

Heckscher, C.. Donnellon, A. (1994). The post-bureaucratic organization. Thousand Oaks: Sage Publications.

Hutchinson. S. (1986). Grounded theory: The method. In P.L. Munhall \& C. J. Oiler (Eds.), Nursing research: A qualitative perspective (pp. 1 l 1-130). Norwalk. CT: Appleton-Century-Crofts.

Kluckhohn, C., Kelly, W. H. (1945). The concept of culture. In R. Linton (Ed). The Science of man in the world crisis. (pp. 788-905). New York.

Kroeber, A. L.. Kluckhohn. C. (1952). Culture: A critical review of concepts and definitions.

Lappe, F., DuBois, P. (1994). The quickening of america. San Francisco: Jossey -Bass Inc.

Lindblom. C. E. (1980). The policy-making process. Englewood Cliffs: Prentice Hall.

Lundberg. C. C. (1985). On the feasibility of cultural intervention in organizations. In P. J. Frost, L. F. Moore, M. R. Louls, C. C. Ludberg, J. Martin 
(Eds.), Organization culture. Beverly Hills, CA: Sage.

Maynard H. B., Mehrtens, S.E. (1993). The fourth wave. San Francisco: Berrat-Koehler.

Mollner, T. (1992). The 21 st-century corporation: the tribe of the relationship age. In J. Renesch (Ed.). New traditions in business. (pp.95 - 106). San Francisco: Berrett-Koehler Publishers.

Morgan, G. (1986). Images of organization. Thousand Oaks: Sage Publishers.

Mumby, D. K. (1988). Communication and power in organizations: discourse, ideology, and domination. Ablex Publishing Corp. Norwood. N.J.

Myers R. E. (1989) Doing Science in Culture: The Social Organization of HBV Screening among Koreans in the Philadelphia Area. Michigan: UMI Dissertation Services. Koehler.

Nair. K. (1994). A higher standard of leadership. San Francisco: Berrett-

Peck, S. M. (1987). The different drum: community making and peace. New York: Simon and Schuster.

Plaskon. P.P. (1993). Chatting over the fence: A qualitative study of cancer and prevention behavior in a high risk rural area. University of Maryland, Health Sciences Library.

Proctor, R.N. (1995). Cancer wars: how politics shapes what we know and don't know about cancer. New York: Basic Books. Praeger.

Rost, J. C. (1993). Leadership for the twenty-first century. Westport, CT:

Schatzman, L., Strauss, A. (1973). Field research: strategies for a natural sociology. Englewood Cliffs, N.J.: Prentice-Hall.

Schein, E. (1985). Organization culture and leadership. San Francisco CA: Jossey-Bass.

Schopler, J. H. (1988). Development and outcomes of externally funded boundary spanning organizations: the community clinical oncology programs. Michigan: UMI Dissertation Services. 
Shaffer, C.R., Anundsen, K., (1993). Creating community anywhere. New York: Putnam.

Singer. S. R., Grismaijer, S. (1995). Dressed to kill:the link between breast cancer and bras. New York: Avery Publishing

Stabiner, K. (1997). To dance with the devil: the new war on breast cancer. N.Y.: Delacorte Press.

Strauss, A. . Corbin. J. (1990). Basics of qualitative research: grounded theory procedures and techniques. Newbury Park. CA: Sage.

Tichy. N. M. (1983). Managing strategic change. New York: Wiley \& Sons.

Tofler, A. (1980). The third wave. N.Y.: William Morrow and Company.

Tylor, E. B. (1871). Primitive culture. Boston. Press.

Whyte, W.F.. Whyte, K.K. (1988). Making mondragon, Ithaca N.Y.: ILR Sage.

Wolcott, H. F. (1994). Transforming qualitative data. Thousand Oaks, CA:

Zakarian, B. (1996). The activist cancer pattent. N.Y.: Wiley \& Sons. 
BCP Culture/Leadership

Appendix A : Figures

95

Reproduced with permission of the copyright owner. Further reproduction prohibited without permission. 


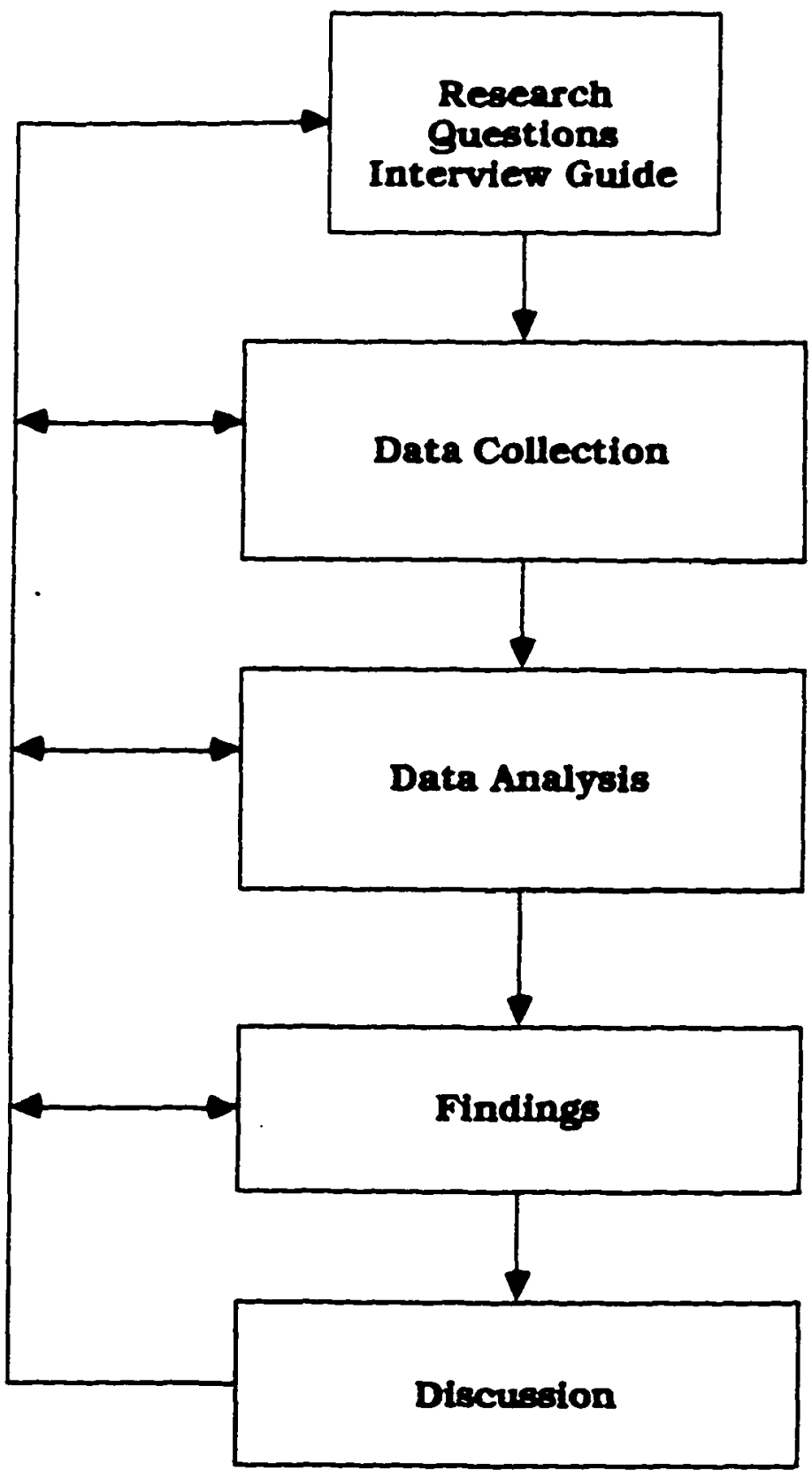

FIGURE III- I : Steps in Research Process A Study of Organization Culture in Breast Cancer Prevention 


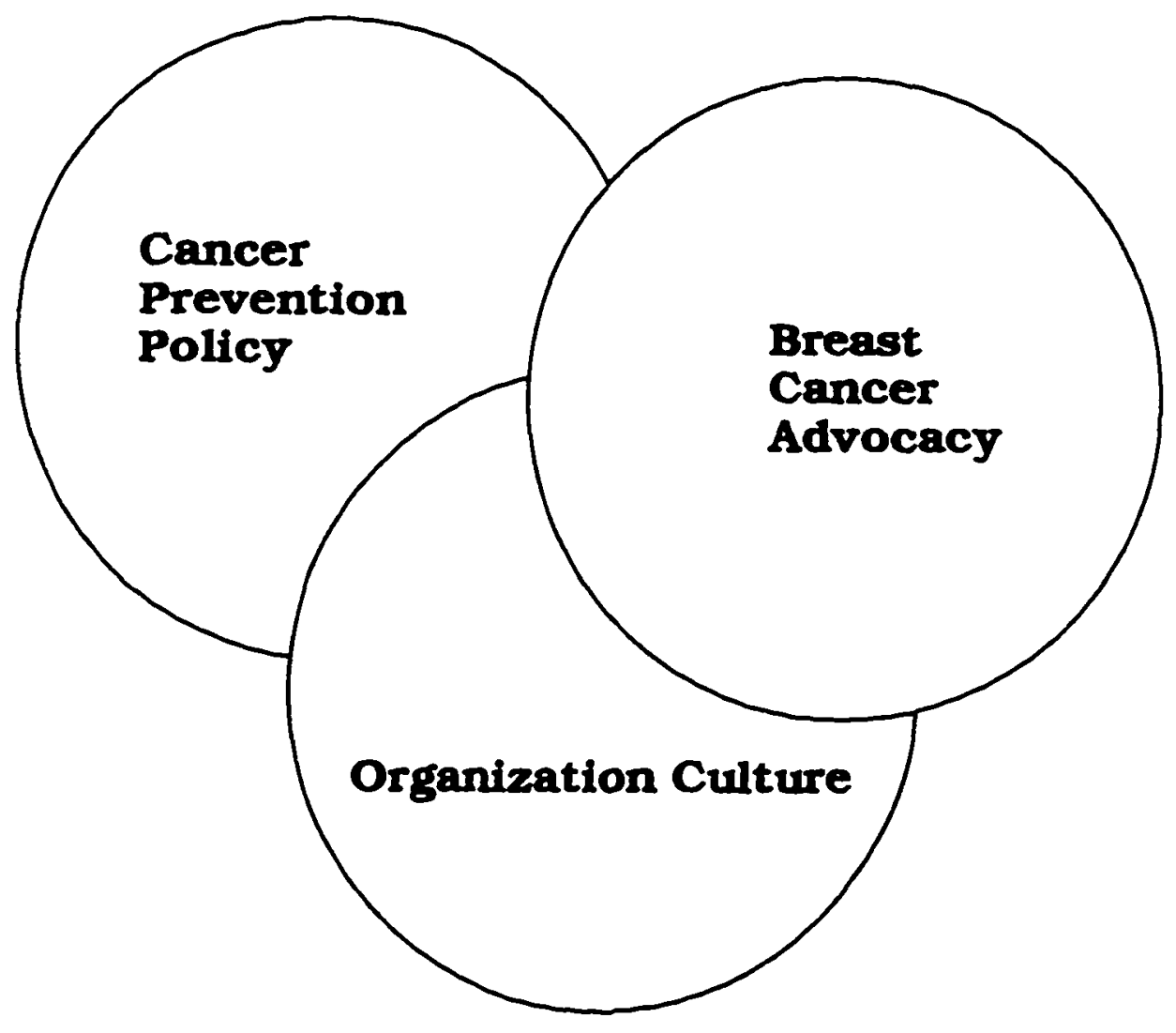

FIGURE III-2: Study Activity Context

A Study of Organization Culture in Breast Cancer Prevention 


\begin{tabular}{|c|c|c|c|c|c|c|}
\hline CULTURE & 1 & 2 & 3 & 4 & 5 & 6 \\
\hline Business & & $x$ & & $x$ & $x$ & \\
\hline Patient Care & & $x$ & & $x$ & $x$ & \\
\hline Clinical Medicine & & $x$ & & & & \\
\hline Conventional Wisdom & $x$ & $x$ & & $x$ & $x$ & \\
\hline Radical Activism & & & & $x$ & & $x$ \\
\hline Political Activism & & & & $x$ & & $x$ \\
\hline Outreacher & & $x$ & $x$ & & & \\
\hline Holistic & & $x$ & $x$ & $x$ & & \\
\hline Researcher Idealism & $x$ & & & & & \\
\hline
\end{tabular}

ARENA LEGEND:

1 - Primary Prevention

2- Secondary Prevention

3- Tertiary Prevention

4- Information Support

5- Funding

6- Advocacy

FIGURE IV-1: Matrix of Formal Connections between Cultures and Arenas A Study of Organization Culture in Breast Cancer Prevention 

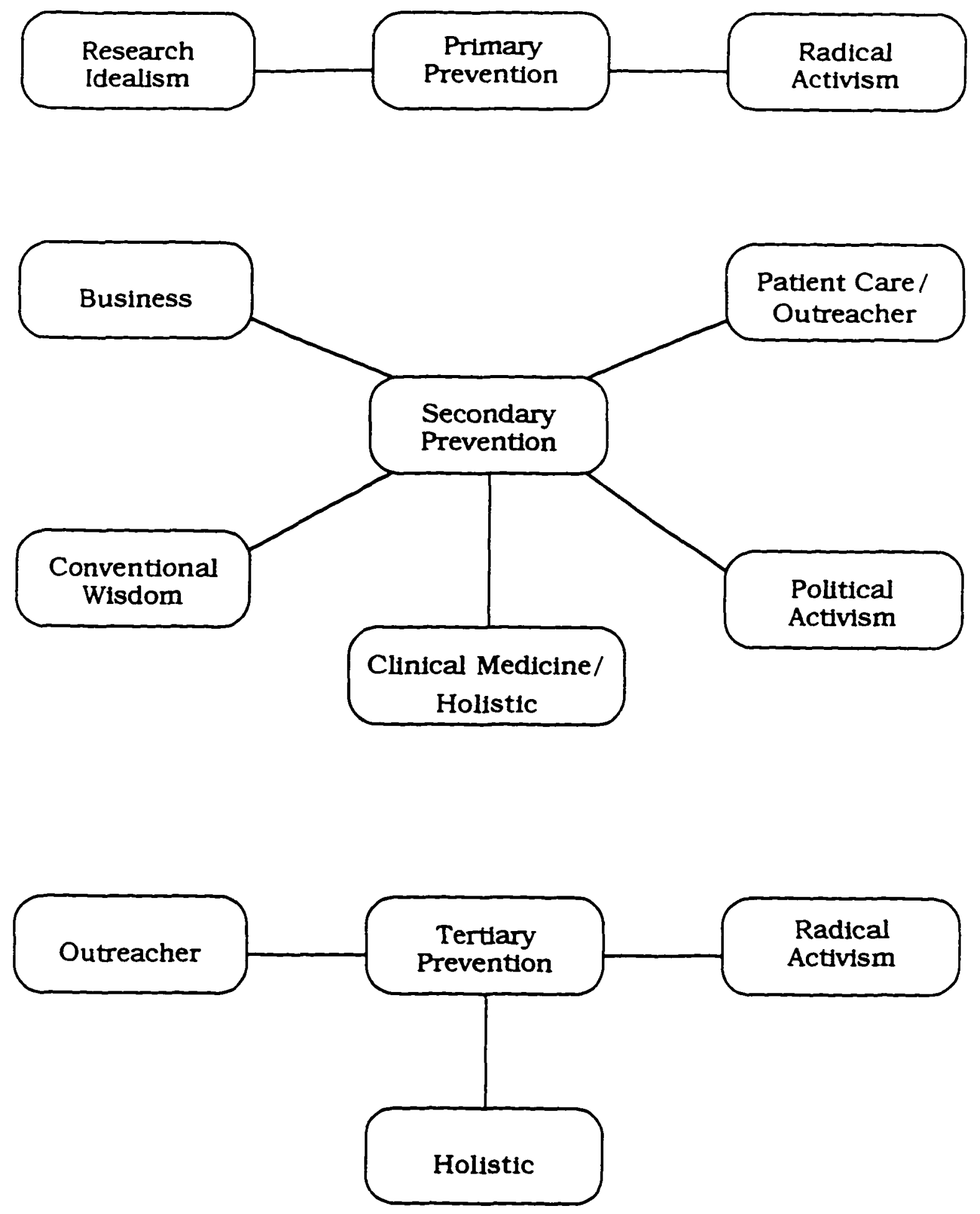

FIGURE IV-2: Support Connections between Cultures and Primary. Secondary. Tertiary Arenas A Study of Organization Culture in Breast Cancer Prevention 


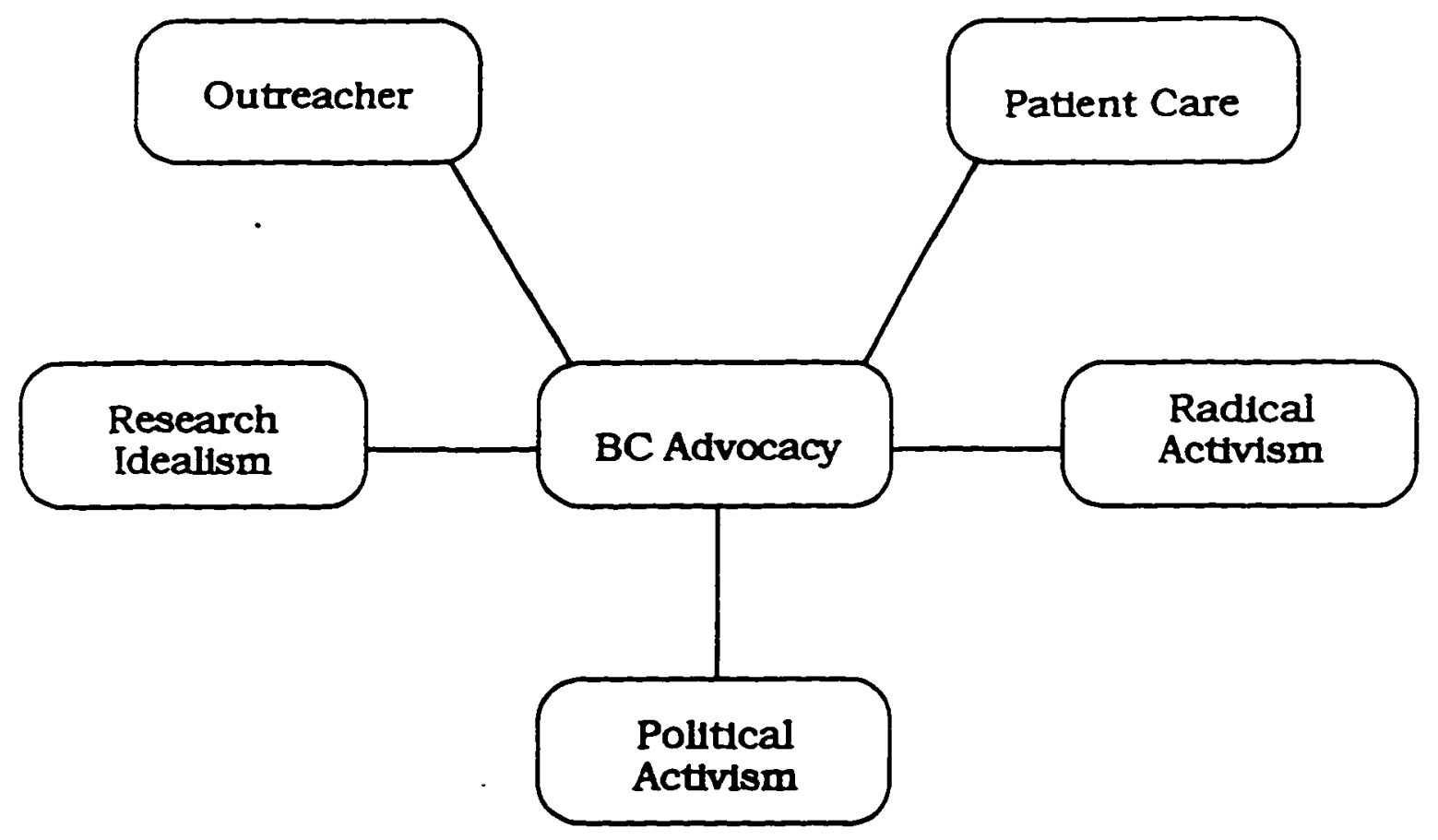

FIGURE IV-3: Informal Connections between Cultures and BC Advocacy A Study of Organization Culture in Breast Cancer Prevention

BC: Breast Cancer 


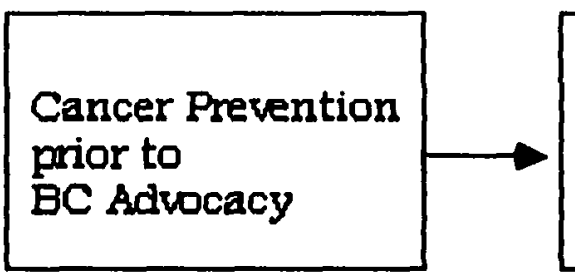

Dominant support to secondary prevention dictated by conventional wisdom and clinical medicine

BC: Breast Cancer

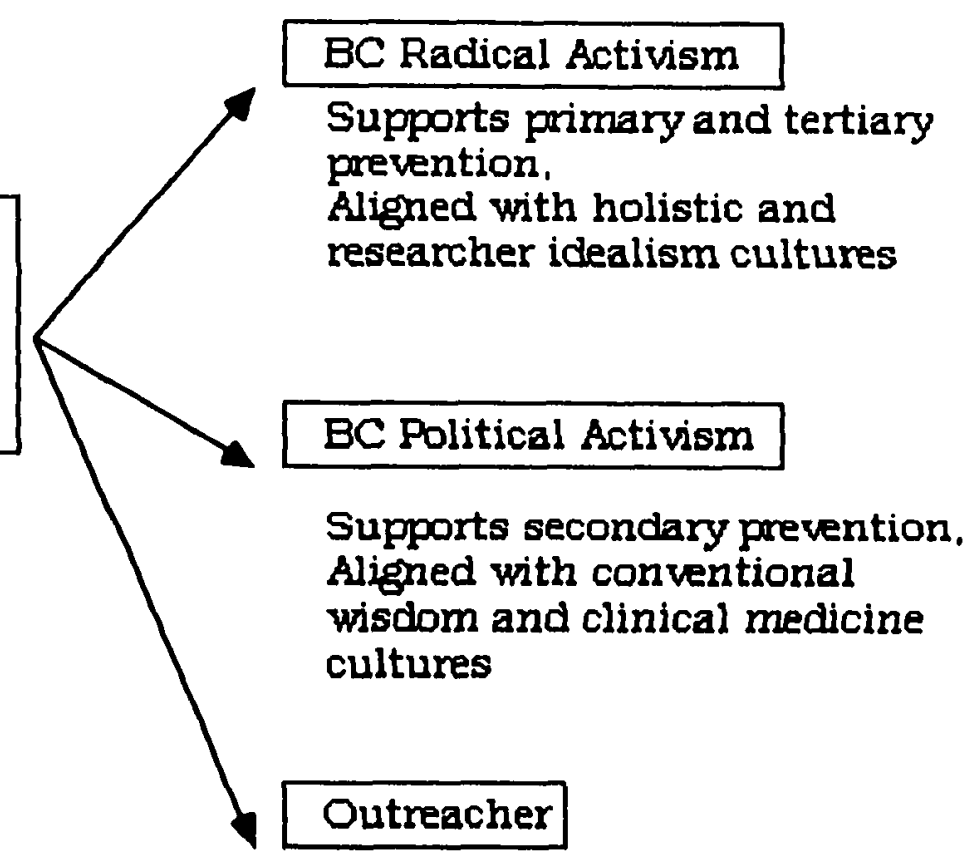

Supports primary, secondary. tertiary prevention:

Aligned with patient care and holistic culture

Figure VI-1: Differentiated Outcomes from Breast Cancer Advocacy A Study of Organization Culture in Breast Cancer PRevention 


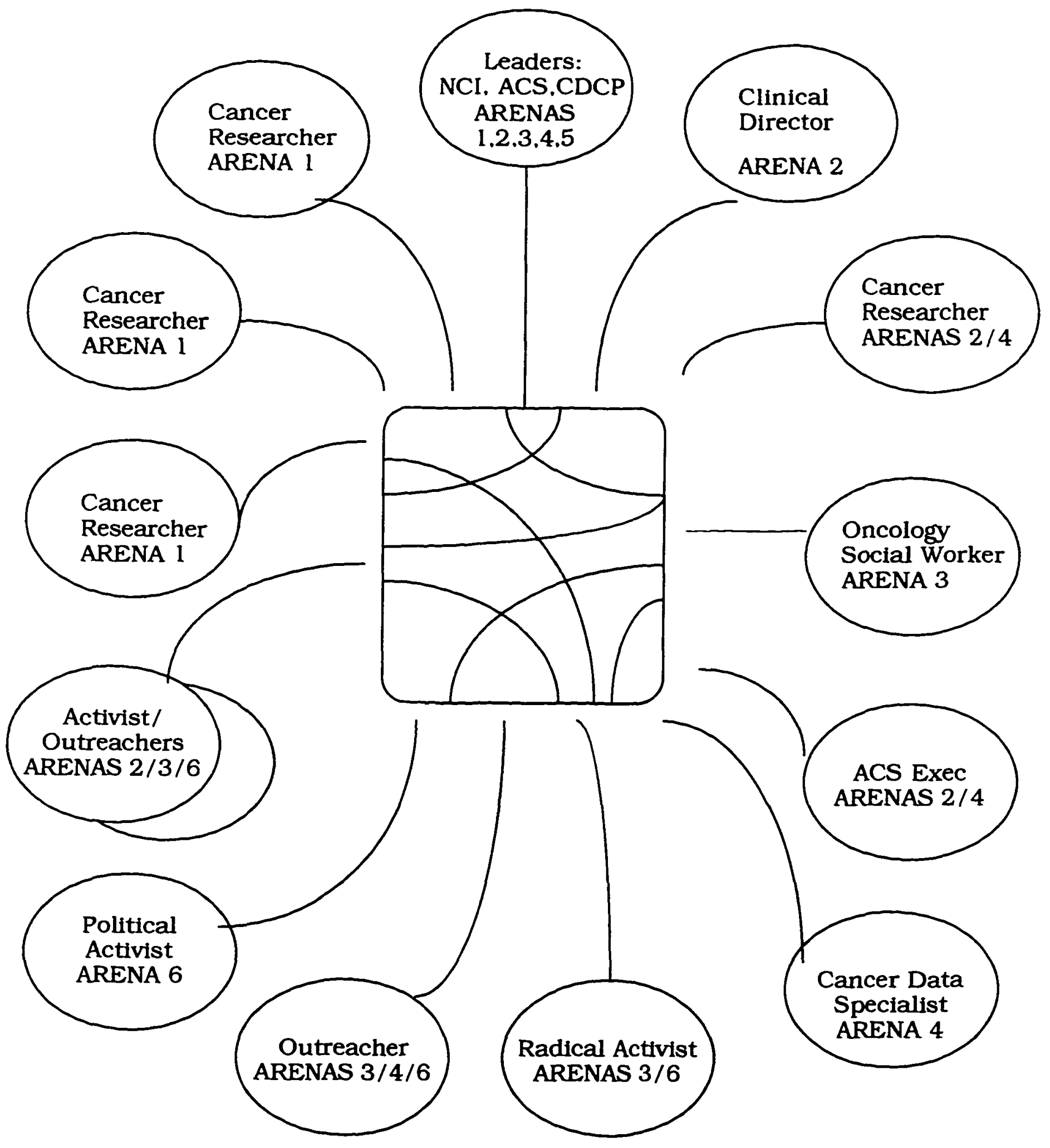

FIGURE VII-1 Collage of Prevention Perspectives A Study of Organization Culture in Breast Cancer Prevention 
BCP Culture/Leadership

\section{Appendix B : Consent Form}




\section{University of San Diego CONSENT TO ACT AS A RESEARCH SUBJECT}

Joseph Raffa is conducting a research study to gather information regarding organization culture, communication, and policy in breast cancer prevention, through interviews with representatives of the community. Since I have been selected to participate in this study, I understand that I will be interviewed. I further understand that the interviews may be taped with no inclusion of names or identifiers.

This data collection will take about 2-3 hours over a period of 8 weeks. Participation in the study should not involve any added risks or discomforts to me except for possible minor fatigue.

My participation in this study is entirely voluntary. I understand I may refuse to participate or withdraw at any time without jeopardy.

I understand my research records will be kept completely confidential. My identity will not be disclosed without consent required by law. I further understand that to preserve my anonymity only group data will be used in any publication of the results of this study.

Joseph Raffa has explained this study to me and answered my questions. If I have other questions or research-related problems, I can reach Dr. Jerome Ammer at (619) 260-4538.

There are no other agreements, written or verbal, related to this study beyond that expressed on this consent form. I have received a copy of this consent document.

I, the undersigned, understand the above explanations and, on that basis, I give consent to my voluntary participation in this research.

Signature of Subject

Date

Location

Signature of Witness

Date

Signature of Researcher

Date 


\section{Appendix C : Definition of Terms}

\section{Definition of Terms}

The terms used in this proposal are defined as follows:

Cancer mortality: Deaths due to cancer morbidity.

Cancer morbidity: The incidence of cancer in the population.

Cancer incidence: The occurrence of a cancer (tumor) in a patient.

Breast Cancer: Cancer that occurs in the breast as a primary tumor.

Organization Culture: Socially constructed realities that influence, and are influenced by, the language, values, norms, folklore, and other social practices that communicate the constructed realities in the organizational environs. Organization Communication: The means, mechanisms, and symbols that transfer ideas, values, norms, and beliefs that inform and form the culture in an organizational setting.

Collaboration: The unifying cooperation and communication that transforms conflict into consensus, and contributes to mission accomplishment.

Policy: The strategic or tactical philosophy, scheme, method that guides decision-making in a particular organizational setting.

Primary Prevention: Prevention with the goal of determining causal factors and ultimately eliminating the disease.

Secondary Prevention: Prevention with the goal of determining means and intervening to decrease the mortality of the disease.

Tertiary Prevention: Prevention that decreases the impact of the disease on the patient and the family, and contributes to decreasing mortality through counseling and information.

Epidemiologist: A researcher that studies disease in the population with a focus on primary prevention (discovery of causal factors).

Oncology Social Worker: A counseling professional that specializes in patients and their families that have experienced cancer or who have concerns related to the disease. e.g., due to symptoms, and/or risk factors. 
BCP Culture/Leadership

\section{Appendix D : Background of Researcher}

The researcher's professional involvement with cancer prevention began in 1985 when he volunteered to assist the University of California, Irvine, to plan and design the system model for statewide mandatory cancer reporting. As a member of the task group to plan the San Diego and Imperial counties regional cancer registry, he developed the proposal to the State Health department, and became the region's first program manager.

In 1990, the researcher collaborated in establishing the first national cancer incidence and treatment data base. funded by the American Cancer Society, and managed by the College of Surgeons. He co-presented a paper on the application of information technology in support of cancer prevention at a 1988 international conference in Venice. Italy.

The researcher conducted grounded theory in breast cancer survivorship in the spring of 1995 as a doctoral student in leadership. The interest generated from his doctoral work in social, cultural and organizational issues has merged with his experience and interest in cancer prevention research, resulting in this dissertation subject.

Prior to 1985. the researcher held management and systems engineering positions with Arinc Research Corp, and General Dynamics. His education includes an M.S. in Industrial Management/Operations Research from Polytechnic University, N.Y., and a B.S. in Industrial Engineering from Pratt Institute, N.Y. 